\title{
Transformar las cosas transitorias en eternas. El obispo Lope de Barrientos y su capilla funeraria en el hospital de la Piedad en Medina del Campo
}

Transforming the Transient into the Eternal. Bishop
Lope de Barrientos and His Funerary Chapel in the
Hospital of la Piedad in Medina del Campo

Diana LuCÍA GÓMEZ-CHACÓN

CSDMM - Universidad Politécnica de Madrid https://orcid.org/0000-0002-0197-7185

diana.lucia@upm.es

\author{
A Fernando Villaseñor Sebastián
}

\begin{abstract}
In 1447 Lope de Barrientos founded his hospital of la Piedad in Medina del Campo, which he appointed his universal heir in 1454. By founding this religious hospital, Barrientos reached the culmination of a life devoted to acts of charity and to the patronage of institutions dedicated to the care of the most disadvantaged. The hospital chapel originally housed the bishop's tomb, which is currently deposited in the Museo de las Ferias in Medina del Campo. The documentary, historical and artistic analysis of this funerary complex allows us to approach, from a new point of view, the distinguished figure of Barrientos, one of the main prelates of $15^{\text {th-century Castile. }}$
\end{abstract}

Keywords: Lope de Barrientos; Medina del Campo; hospital; funerary chapel.
Resumen: En 1447 Lope de Barrientos fundó su hospital de la Piedad en Medina del Campo, al cual nombró su heredero universal en 1454. Con esta fundación hospitalaria, Barrientos culminaría una vida consagrada a la reforma de la piedad cristiana, a los actos de caridad y al patrocinio de instituciones destinadas al cuidado de los más necesitados. La capilla del hospital albergó la tumba del obispo, cuyos restos se conservan hoy en día en el Museo de las Ferias de Medina del Campo. El análisis documental, histórico y artístico de este desaparecido conjunto funerario nos permitirá aproximarnos, desde un nuevo punto de vista, a la figura de Barrientos, uno de los principales prelados de la Castilla del siglo XV.

Palabras clave: Lope de Barrientos; Medina del Campo; hospital; capilla funeraria.

* Este trabajo se enmarca en el proyecto de investigación Promoción artística y cultura cortesana en Castilla durante los reinados de fuan II y Enrique IV (1405-1474) (HAR2017-82170-P) (MINECO/ AEI/FEDER, UE). 


\section{INTRODUCCIÓN}

El 18 de abril de 1447 fray Lope de Barrientos (ca. 1382-1469), obispo de Cuenca (1445-1469), solicitó permiso a Nicolás V (1447-1455) para fundar un hospital en Medina del Campo -villa de la que era natural-, pensando en su propia salvación y deseando transformar las cosas transitorias en eternas ${ }^{1}$, declaración de intenciones cargada de simbolismo que da título a este trabajo y sobre la que volveremos más adelante. Años más tarde, el 17 de noviembre de 1454, fray Lope de Barrientos (ca. 1382-1469), nombró heredero universal al hospital de Santa María de la Piedad en Medina del Campo (fig. 1) ${ }^{2}$. Su independencia y solvencia económicas permitieron que el hospital fundado por Barrientos fuese el único en no verse afectado por la decisión tomada el 10 de septiembre de 1587 por Felipe II (1556-1598) de reducir todos los centros asistenciales de Medina del Campo a un único hospital general: «Este hospital no os pide nada, ni vosotros se lo dais, y con lo que tiene os cura vuestros enfermos. Dejadle conservar la memoria de su fundador» ${ }^{3}$.

Lope de Barrientos, también conocido como Lope de Medina, fue obispo de Segovia (1438-1441), Ávila (1441-1445) y Cuenca (1445-1469), canciller del rey Juan II de Castilla (1406-1454), confesor real, oidor de la audiencia y miembro del Consejo real. Nació a finales del siglo XIV en Medina del Campo, en el seno de una familia de caballeros ${ }^{4}$. Algunos autores aseguran que fue hijo de Pedro Gutiérrez de Barrientos, quien acompañó a Fernando de Antequera

1 A pesar de que la fundación del hospital de la Piedad de Medina del Campo se ha venido fechando en 1455, Nicolás v había ya aprobado la creación y dotación de este centro de asistencia hospitalaria el 18 de abril de 1447: Eugenio FonTaneda PÉREZ, El Hospital de la Piedad y San Antonio Abad o del obispo de Barrientos, en Eufemio Lorenzo, Historia de Medina del Campo y su tierra, vol. I, Nacimiento y expansión, Valladolid, 1986, pp. 429-450, pp. 433 y 435.

2 Paloma Cuenca MuÑoz, El legado testamentario de Lope de Barrientos, en Espacio, Tiempo y Forma. Serie III. H. ${ }^{a}$ Medieval, 9 (1996), pp. 303-326, p. 322.

3 Gerardo Moraleja Pinilla, Historia de Medina del Campo, Medina del Campo, 1971, p. 438; María José Díez Hermano, Escribir para administrar: los censos del Hospital de la Piedad de Medina del Campo en época moderna, en Funciones y prácticas de la escritura. I Congreso de Investigadores Nóveles en Ciencias Documentales, Madrid, 2013, pp. 49-56, pp. 49 y 50, nota 9.

4 Juan Carlos Moreno Moreno, Los linajes de Medina del Campo. Concesión de un nuevo linaje a fray Lope de Barrientos, 1454, en Lope de Barrientos. Seminario de cultura, 2 (2009), pp. 141-154, p. 151; Francisco de Paula CAÑAS GÁlvEZ, El itinerario de la Corte de fuan II de Castilla (1418-1454), Madrid, 2007, p. 148, nota 614; Óscar VILLARROEL GONZÁLEZ, Las elecciones episcopales en la primera mitad del siglo XV. Realidad y representación de la «Libertas» eclesiástica, en Juan Francisco JIMÉNEZ, Jorge ORTUÑo y Jorge A. EIROA, Actas I Simposio de fóvenes Medievalistas, Murcia, 2003, pp. 261273, p. 266; Óscar VILlaRROel GONZÁLEZ, El rey y la Iglesia castellana. Relaciones de poder con Fuan II (1406-1454), Madrid, 2011, pp. 106, 117, 121, 126, 153-155 y 570-574. 


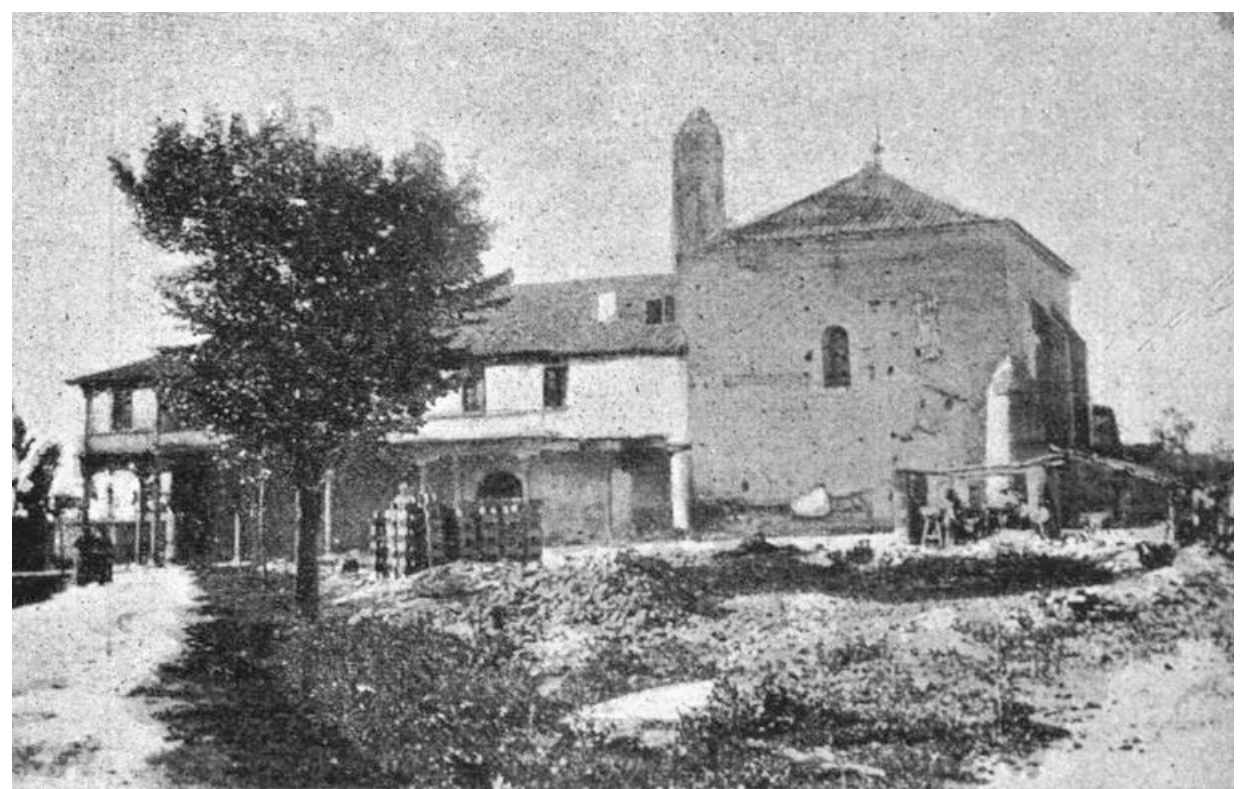

Figura 1. Hospital de la Piedad en Medina del Campo, 1901. Fotografía de José Martí y Monsó.

en la campaña de Andalucía y falleció defendiendo la frontera el 21 de octubre de 1407, hecho que justificaría la protección que el regente de Castilla y futuro rey de Aragón brindó en todo momento a la familia Barrientos ${ }^{5}$. En efecto, fray Lope mantuvo, a lo largo de toda su vida, una estrecha relación con el infante Fernando, señor de Medina del Campo y fundador del convento dominicano de San Andrés, en el que Barrientos profesó ${ }^{6}$. Además, el dominico habría formado parte del séquito que acompañó a Fernando de Antequera a Morella a reunirse

5 Paloma Cuenca MuÑoz, Lope de Barrientos. Tratado de la divinança, tesis doctoral, Universidad Complutense de Madrid, 1992, p. 6; Ángel MARTíneZ CASADO, Lope de Barrientos. Un intelectual en la corte de fuan II, Salamanca, 1994, pp. 17-19; María Isabel GARCíA-Monge CARRETERO, Estudio y edición crítica del «Tratado del dormir y despertar» de Lope de Barrientos, tesis doctoral, Universidad Complutense de Madrid, 2001, p. 15.

6 Desgraciadamente no se conservan restos del mencionado convento medinense. Según ha señalado Antonio Sánchez del Barrio, en 1508 un incendio asoló «todo el convento y depósito y todas sus escrituras». El edificio primitivo, reconstruido en 1575, habría tenido una «torre vana» y varias capillas. Junto al convento se levantaban unas casas reales de tiempos de Juan II de Aragón, que fueron posteriormente cedidas a la familia de los Rejones. Además, sabemos que los dominicos regentaron un hospital y una hospedería titulados de igual forma que el convento: Antonio SÁNCHEZ DEL BARRIO, Historia y evolución urbanística de una villa ferial y mercantil. Medina del Campo entre los siglos XV y XVI, tomo I, tesis doctoral, Valladolid, 2005, pp. 301 y 302. 
con Benedicto XIII en el verano de $1414^{7}$. Años más tarde, en el otoño de 1429, entre el 8 de septiembre y el 22 de noviembre, tras haber completado sus estudios e impartir clases de Teología en Salamanca ${ }^{8}$, Juan II le nombró preceptor del príncipe Enrique, futuro Enrique IV ${ }^{9}$.

Si bien, como ha señalado José Manuel Nieto Soria, Lope de Barrientos, quizás no responda enteramente a lo que podría considerarse como un «obispo reformado», lo cierto es que constituye un exponente típico de la actividad reformadora emprendida por algunos de los principales eclesiásticos al servicio de la realeza Trastámara ${ }^{10}$. Además, fue uno de los primeros Predicadores en implicarse en la reforma de su orden, probablemente influido por el espíritu observante de otros dominicos del entorno regio, como fray Alonso de Cusanza, fray Álvaro de Córdoba, fray Luis de Valladolid y fray Juan de Torquemada ${ }^{11}$.

En el presente trabajo se analizará, precisamente, una de las principales consecuencias de dicho afán reformador, a la que apenas se le ha prestado la debida atención en los diversos trabajos centrados en la figura de Barrientos y a la que, sin embargo, consagró gran parte de su vida, y principalmente, de su vejez: las obras de caridad, y, más concretamente, la creación de instituciones asistenciales u hospitalarias, constituyendo el mejor ejemplo de ello, la fundación de su ya citado hospital de la Piedad en Medina del Campo, el cual habría de convertirse en su lugar de enterramiento. El estudio de su capilla funeraria, uno de los proyectos más personales y ambiciosos de Barrientos, nos permitirá aproximarnos -a través de la revisión de la documentación conservada y de las escasas descripciones que

7 Luis G. Alonso-Getino, Vida y obra de Fr. Lope de Barrientos, Salamanca, 1927, p. 190; Ángel MARTÍNEZ CASADO, Lope de Barrientos... [ver n. 5], p. 19, nota 6. Sobre las visitas a Morella véase Luis SUÁREZ FERNÁNDEZ, Castilla, el Cisma y la crisis conciliar (1378-1440), Madrid, 1960, pp. 6971; Óscar VILlarRoel GONZÁleZ, El rey y el papa. Política y diplomacia en los albores del Renacimiento (el siglo XV en Castilla), Madrid, 2009, pp. 42 y 49; Francisco Javier MOLINA DE LA TORRE, Epigrafía medieval y moderna en la provincia de Valladolid (987-1556), tesis doctoral, Universidad de Valladolid, 2013, p. 449.

8 Como ha señalado Ángel Martínez Casado, es muy probable que durante su estancia en Salamanca coincidiese con el futuro cardenal Juan de Torquemada, quien se alzó como uno de los grandes defensores de la reforma de la Orden de Predicadores: Ángel MARTínEZ CASAdo, Lope de Barrientos... [ver n. 5], p. 21. Véase también Águeda M. RodRÍGUEZ CRUZ, Historia de la Universidad de Salamanca, Salamanca, 1990, p. 59.

9 Juan de Mata Carriazo Arroquía (ed.), Refundición de la Crónica del Halconero, Madrid, 1946, p. 83; Ángel MARTÍNEZ CASADO, Lope de Barrientos... [ver n. 5], pp. 22-23; Luis G. ALONSO-GETINO, Dominicos españoles confesores de reyes, en Ciencia Tomista, XIV, 41-42 (1916), pp. 374-451, p. 409.

10 José Manuel NIETO SORIA, Los proyectos de reforma eclesiástica de un colaborador de fuan II de Castilla: el obispo Barrientos, en Tomás Quesada Quesada. Homenaje, Granada, 1998, pp. 493-516, p. 513.

11 Ibid., pp. 494-495 y 510-511. 
han llegado hasta nosotros del mencionado espacio funerario, así como de un detenido examen de los restos conservados- a uno de los personajes más destacados de la Castilla del siglo XV, tratando de dejar a un lado su habitual condición de prelado a la sombra del rey, en un intento de perfilar los intereses tanto devocionales como artísticos de tan destacado obispo.

\section{LOPE DE BARRIENTOS Y EL EJERCICIO DE LA CARIDAD: SUS FUNDACIONES HOSPITALARIAS}

Las inquietudes de Barrientos en lo relativo a la reforma de las órdenes religiosas, así como de la piedad cristiana, se vieron materializadas, en gran medida, en su empeño en favorecer la creación de centros hospitalarios ${ }^{12}$, concebidos en época medieval como una institución para la práctica de la caridad ${ }^{13}$. En efecto, el hospital de la Piedad de Medina del Campo, sobre el que me detendré más adelante, fue, sin lugar a dudas, la principal fundación hospitalaria del obispo Barrientos, pero no la única. La historiografía de la Universidad de Salamanca se hace eco de una tradición que atribuye a fray Lope de Barrientos la construcción del Hospital del Estudio, bajo la advocación de santo Tomás de Aquino, iniciativa que habría sido aprobada por Juan $\mathrm{II}^{14}$ el 30 de marzo de $1413^{15}$. No obstante, no

12 José Manuel NieTO SORIA, Los proyectos de reforma... [ver n. 10], p. 508.

13 Con las fundaciones de hospitales en época medieval se pretendía ofrecer soluciones a los problemas sociales, paliar las necesidades del pobre, mantener la estructura ordenada de la sociedad y hacerse merecedores de la salvación eterna, para lo cual, los pobres - pauper alter Christus- eran considerados intermediarios eficaces: Mercedes GALLENT MARCO, Historia e bistoria de los hospitales, en Revista d'bistoria medieval, 7 (1996), p. 184; Carmen LóPEZ ALONSO, La pobreza en la España medieval. Estudio Histórico-Social, Madrid, 1986, p. 407 y ss.

14 «Juan II...dio un palacio contiguo para hospital del estudio que en memoria suya se dedicó á S. Juan»: José María QUADRADO, Recuerdos y Bellezas de España. Salamanca, Ávila y Segovia, Barcelona, 1865, p. 98. A pesar de las palabras de Quadrado, parece ser que el hospital se dedicó a santo Tomás de Aquino, santo dominicano: José Ramón NIETO GONZÁLEZ, Escuelas Mayores, Menores y Hospital del Estudio, siglos XIII-XX, en Luis E. RODRÍGUEZ-SAN PEDRO BEZARES (coord.), Historia de la Universidad de Salamanca, vol. II: Estructuras y flujos, Salamanca, 2004, pp., 375-456, p. 450.

15 Fernando ARaujo, La Reina del Tormes. Guía histórico-descriptiva de la ciudad de Salamanca, Salamanca, 1884, tomo I, p. 87 y tomo II, p. 172; Vicente BELTRÁN DE HEREDIA, Bulario de la Universidad de Salamanca, Salamanca, 1966, tomo I, p. 258; ID., Cartulario de la Universidad de Salamanca. La Universidad en el Siglo de Oro, tomo II, Salamanca, 1970, p. 199; Teresa SANTANDER RodrígueZ, El Hospital del Estudio, en Luis E. RodríGUEZ-SAN PEDro BEZARES y Juan Luis POlO RodrígueZ (eds.), Historia de la Universidad de Salamanca, III.1. Saberes y confluencias, Salamanca, 2006, pp. 361-388, p. 362; Julián ÁLVAREZ VILLAR, La Universidad de Salamanca. Arte y tradiciones, Salamanca, 1993, p. 39. 
ha sido posible documentar dicha intervención ${ }^{16}$. De hecho, José Ramón Nieto González asegura que «el promotor de este Hospital fue fundamentalmente la Universidad y no el poder real ni fray Lope de Barrientos, confesor de Juan II, como tradicionalmente se había afirmado» ${ }^{17}$.

Ya como obispo de Cuenca, Barrientos habría mandado edificar la ermita y hospital de San Sebastián, extramuros de la ciudad ${ }^{18}$. El 27 de junio de 1446, consciente de que el cabildo conquense se beneficiaba de diezmos que no le correspondían, pertenecientes a la mesa episcopal de la Serranía de Cuenca, el obispo accedió a que estos se siguiesen percibiendo siempre y cuando se destinasen al sostenimiento de una casa hospital para pobres, que recientemente había donado al cabildo y de la que, lamentablemente, no se aportan más datos ${ }^{19}$.

Mejor documentada se encuentra la fundación del hospital conquense de Nuestra Señora Santa María de la Consolación. El 22 de diciembre de 1447 el obispo Barrientos «considerando que avemos de dar cuenta a Dios de los muchos beneficios que nos ha dado en esta presente vida, e queriéndolos expender en obras de caridad» manda «fazer un hospital para resçibir los pobres, adonde se podrán, con el ayuda de nuestro señor Dios, conplir todas las siete obras de misericordia corporales $»^{20}$. Para ello ordena edificar el hospital sobre las casas que sirvieron de morada al arcediano de Alarcón, don Ruy Bernal, que se encontraban «cerca del postigo, detrás de nuestros palaçios» ${ }^{21}$. En la misma acta capitular se indica que dicho hospital habría de quedar unido a la «helemosina de la dicha nuestra eglesia», es decir, al Arca de la Limosna de la catedral de Cuenca ${ }^{22}$, institución creada entre 1396 y 1399, durante los primeros años del obispado de Juan Cabeza de Vaca (1396-1407)23.

Sabemos que las sucesivas autorizaciones pontificias concedidas a Barrientos entre 1438 y 1461 le permitieron invertir sus haberes y hacienda en obras be-

16 Ángel Martínez CASAdo, Lope de Barrientos... [ver n. 5], p. 21.

17 José Ramón NieTo GonZÁLEZ, Escuelas Mayores, Menores y Hospital del Estudio... [ver n. 14], p. 451.

18 Gema PAlOmo Fernández, La catedral de Cuenca en el contexto de las Grandes Canterías Catedralicias Castellanas en la Baja Edad Media, tomo II, Cuenca, 2002, p. 54; Jorge DÍAZ IBÁÑEZ, Pobreza y marginación en la Castilla bajomedieval. Notas sobre el ejercicio de la caridad en Cuenca a fines de la Edad Media, en Anuario de Estudios Medievales, 24 (1994), pp. 887-924, pp. 896 y 900; ID., La Iglesia de Cuenca en la Edad Media (siglos XII-XV). Estructura institucional y relaciones de poder, tesis doctoral, Universidad Complutense de Madrid, 1996, p. 190.

19 José Manuel NIETO SORIA, Los proyectos de reforma... [ver n. 10], p. 509.

20 Gema Palomo FernándeZ, La catedral de Cuenca..., tomo II [ver n. 18], doc. 33, p. 340.

21 Ibid., tomo II, doc. 33, p. 340.

22 Ibid., tomo II, pp. 54 y 340.

23 Jorge DíAZ IBÁÑ̃E, La Iglesia de Cuenca... [ver n. 18], p. 320. 
néficas y en la gratificación de sus familiares. Es probable que buena parte de las rentas, tanto episcopales como reales, de las que Lope de Barrientos se apoderó entre 1468 y 1469, fuesen invertidas en la asistencia a los pobres ${ }^{24}$. Parece, incluso, haber sido costumbre de este prelado lanzar al mercado, a un bajo precio, las rentas en grano del obispado, con la intención de ampliar la demanda, facilitando el abastecimiento de la población menos favorecida y evitando o, al menos, paliando, el alza de los precios. De esta forma, habría tratado de reducir los efectos de la especulación y el acaparamiento ${ }^{25}$.

Las fundaciones hospitalarias de Lope de Barrientos se produjeron en un momento en el que las instituciones asistenciales vieron flaquear sus recursos al aumentar la miseria. Los hospitales subsistían gracias a sus bienes raíces, pero las rentas y censos sufrieron un importante descenso entre mediados del siglo XIV y el primer tercio del $\mathrm{XV}$. Los donantes, afectados por la crisis económica, redujeron sus limosnas y legados, llegando incluso a sustituir estos por fundaciones de misas, movidos por la preocupación de su propia salvación ${ }^{26}$. No obstante, san Vicente Ferrer (ca. 1350-1419), seguía animando a los fieles a visitar hospitales y practicar la caridad con los enfermos que allí estuviesen siendo atendidos: «devem haver compassió dels malalts: així, vullam visitar los espitals e dar alguna almoina ${ }^{27}$.

En el Archivo de la Catedral de Cuenca se conserva una de las varias copias redactadas en el verano de 1471 del dictamen pronunciado por una comisión del claustro de la Universidad de Salamanca, a petición del deán y cabildo de Cuenca. Según consta en el mencionado documento, a la muerte de «domino Lupus, dicte ecclesie episcopus» $\mathrm{y}$, por lo tanto, con la sede vacante, el cabildo había vendido cierta cantidad de trigo procedente de las rentas de la mesa episcopal, rentas que entonces eran reclamadas por Antonio Jacobo de Véneris (1470-1479), sucesor de Barrientos en la mitra conquense ${ }^{28}$. Como apuntó Santiago Aguadé Nieto, la actuación del cabildo de Cuenca en el verano de 1469 habría tenido como claro antecedente la política del propio obispo Barrientos. Ante la resolución dada por la comisión salmantina, cuyos miembros respaldaban plenamente la iniciativa del

24 Santiago AgUAdÉ NiETo, Crisis de subsistencia, rentas eclesiásticas y caridad en la Castilla de la segunda mitad del siglo XV, en Estudios en memoria del Profesor D. Salvador de Moxó, tomo I, Madrid, 1982, pp. 21-48, pp. 35-36.

25 Ibid., p. 35; Jorge DÍAZ IbáÑEZ, Pobreza y marginación, p. 909; ID., La Iglesia de Cuenca, p. 190.

26 Michel Mollat, Pobres, humildes y miserables en la Edad Media. Estudio social, México D.F., 1988, p. 243.

27 San Vicente Ferrer, Sermons de Quaresma, vol. I, Valencia, 1973, p. 190; Agustín Rubio Vela, Pobreza, enfermedad y asistencia hospitalaria en la Valencia del siglo XIV, Valencia, 1984, pp. 15-16.

28 Santiago Aguadé Nieto, Crisis de subsistencia... [ver n. 24], pp. 22-23. 
cabildo conquense, basándose en diversos argumentos, entre ellos, la obligatoriedad de la caridad, Aguadé Nieto señaló la posibilidad de que la constante preocupación de Lope de Barrientos por el ejercicio de la caridad, fuese, en gran parte, reflejo del clima universitario en el que se formó y que él mismo se habría encargado de promover y difundir. Recordemos que Barrientos cursó sus estudios en la Universidad de Salamanca y que algunas fuentes lo consideran el primer catedrático de prima de teología que tuvo la Orden de Predicadores en la misma ${ }^{29}$.

\section{El hospital De la PiedAD DE MEDinA DEL CAMPO}

A pesar de que, como ha señalado Carmen López Alonso, en época medieval la muerte fuese el momento privilegiado que se elige para el ejercicio de la caridad $^{30}$, en el caso de Lope de Barrientos, como hemos visto, esta parece haber sido una constante en su vida y, en especial, a lo largo de su episcopado en Cuenca, durante el cual, su actividad como fundador de instituciones asistenciales culminó con la creación del hospital de Santa María de la Piedad de Medina del Campo ${ }^{31}$.

Lorne Campbell y Juan José Pérez Preciado han apuntado que, a pesar de que el 11 de agosto de 1451, el 29 de septiembre de 1452 y el 24 de marzo de 1453, Lope de Barrientos obtuvo indulgencias plenarias in articulo mortis para todos los pobres, enfermos y servidores que murieran en el hospital ${ }^{32}$, en 1455 el obispo residía todavía en el convento de San Andrés de Medina del Campo ${ }^{33}$ y no en el hospital, lo que, según los mencionados autores, se debería al lento avance de las obras ${ }^{34}$. Sin embargo, no podemos descartar la posibilidad de que Barrientos nunca pretendiese fijar su residencia en el hospital y prefiriese permanecer junto a la comunidad de religiosos del convento del que era hijo, el cual, por otro lado, se encontraba, en

29 Ibid., pp. 40-43 y 46.

30 Carmen López AlONSO, La pobreza... [ver n. 13], p. 494.

31 Este hospital habría tenido agregada una ermita próxima dedicada a san Alejo: Antonio SÁNCHEZ DEL BARRIO, Historia y evolución urbanística... tomo I [ver n. 6], p. 230.

32 Vicente Beltrán DE Heredia, Bulario... tomo III [ver n. 15], doc. 1131, p. 54 y doc. 1140, p. 65; Ángel MARTínez CASADO, Lope de Barrientos... [ver n. 5], doc. 23, pp. 233-234.

33 Un documento del 17 de mayo de 1455 aparece datado «Apud monasterium beati Andree, opido de Metina, in domo habitationis nostre»: Ángel MARTíNEZ CASADO, Lope de Barrientos... [ver n. 5], p. 63 , nota 5 .

34 Lorne CAMPBell y Juan José PÉRez Preciado, Egas Cueman, Fray Lope de Barrientos, en Lorne CAMPBEll (ed.), Rogier van der Weyden y los reinos de la península Ibérica, Madrid, 2015, p. 171. 
origen $^{35}$, muy próximo al hospital de la Piedad ${ }^{36}$. En la carta de pregones de Juan II del 29 de junio de 1454 se indica que Lope de Barrientos «ha fecho e edificado e constituydo vn notable hospital en la villa de Medina del Campo llamado de Santa María de la Piedad», lo que indicaría que para entonces las obras se encontraban ya concluidas. Por su parte, Ángel Martínez Casado afirma que en 1451 el edificio estaba ya terminado puesto que, al avalar Juan II la súplica que Barrientos envió al pontífice ese mismo año, el monarca arguye que el hospital ya estaba construido, suficientemente dotado y que atendía diariamente a numerosos pobres que llegaban a Medina del Campo atraídos por sus ferias. Además, en la mencionada carta de pregones, el monarca ordena que los 25.000 maravedís de juro de heredad con los que don Álvaro de Luna había dotado su capilla en la catedral de Toledo, pasen al hospital de la Piedad de Medina del Campo:

Commo quier que yo podría disponer dello commo de cosa mía, pero porque ya vna vez fueron dedicados para obra pía, quiero e es mi voluntad que asimismo sean tornados e conuertidos en otra obra pía, e considerando quel rreuerendo padre don Lope de Barrientos, obispo de Cuenca [...] ha fecho e edificado e constituydo vn notable hospital en la villa de Medina del Campo llamado de Santa María de la Piedad, en el qual se recogen e aluergan los pobres e fazen en él muchas limosnas e obras caritatiuas e de misericordia e piedad, conplideras a seruiçio de Dios e a bien e sostenimiento de los pobres e salud de las ánimas, e porque tengan cargo de rrogar a Dios por las ánimas del rrey don Enrrique e de la rreyna doña Catalina, mis señores padre e madre que santo paraíso ayan ${ }^{37}$.

Lope de Barrientos habría pretendido, a través de esta fundación hospitalaria, obtener beneficios espirituales de los cuales iba a poder seguir disfrutando después de su muerte, tal como queda reflejado en la petición que envía a Nicolás $\mathrm{V}$ solicitando la licencia del pontífice, en la que afirma que manda levantar este hospital «pensando en su propia salvación y deseando transformar las cosas terrenales en celestiales, y las cosas transitorias en eternas» ${ }^{38}$. Según indican sus

35 En 1835, y, en gran medida, como consecuencia del incendio producido el 20 de septiembre de 1810 causado por la infantería francesa que se hallaba acuartelada en el interior del convento, la comunidad de religiosos se vió obligada a trasladarse al Palacio de la Condesa de Bornos: Eugenio FonTANeda PÉREZ, El Hospital de la Piedad... [ver n. 1], pp. 432 y 433.

36 En las Constituciones y Ordenanzas del Hospital de la Piedad de Medina del Campo se nos dice que este se encontraba «cerca del monasterio de San Andrés de la dicha villa»: Eugenio FONTANEDA PÉREZ, El Hospital de la Piedad... [ver n. 1], p. 442.

37 Ángel MARTínez CASADO, Lope de Barrientos... [ver n. 5], doc. 26, pp. 247-248.

38 Vicente Beltrán de Heredia, Bulario... tomo III [ver n. 15], pp. 9-10; María José Díez HerMANO, Escribir para administrar... [ver n. 3], p. 49, nota 6; Ángel MARTÍNEZ CASADO, Lope de Barrientos... [ver n. 5], p. 87. 
Constituciones, esta fundación habría de ser destinada a la atención de los enfermos pobres sin dolencias crónicas ${ }^{39}$-prohibiéndose el ingreso de todo aquel que no fuese pobre, enfermo o servidor de la propia institución ${ }^{40}$, la limosna a los pobres, la educación de los niños abandonados, la celebración de los oficios litúrgicos y la instrucción teológica ${ }^{41}$. En relación a este último punto, cabe señalar que el maestro encargado de impartir las lecciones de teología, en latín o castellano, entre el 1 de enero y el 8 de septiembre, habría de ser un religioso del convento de San Andrés, el cual recibiría por su labor 5.000 maravedís anuales, es decir, 1.000 maravedís más que el propio rector del hospital ${ }^{42}$.

La relevancia alcanzada por este centro asistencial desde su fundación, el cual se convierte en un modelo a seguir para futuras instituciones hospitalarias, queda puesta de manifiesto en el testamento de don Pedro García Herrera (3 de enero de 1455), mariscal de Castilla, miembro del consejo del rey y sobrino de Sancho de Rojas, arzobispo de Toledo, quien funda en su villa de Ampudia de Campos el hospital de Santa María de la Clemencia, en el cual, los pobres en él atendidos, habrían de ser regidos «por vía de ordenanza que están los pobres de la Cofradía de Esgueva de Valladolid, y del Hospital que tiene fecho el Conde de Haro en Medina de Pomar, o del Hospital de Medina del Campo que hace el Obispo de Cuenca» ${ }^{43}$.

Algunos años más tarde, Diego Arias de Ávila fundó el hospital de San Antonio de Padua en Segovia, destinado al acogimiento de indigentes y concebido como escaparate de la piedad y de la riqueza de su linaje, cuyas obras estarían terminadas a mediados de febrero de $1460^{44}$. Si bien Arias de Ávila, al contrario que Lope de Barrientos, no mandó ser enterrado en su hospital, sí fundó una capilla funeraria en el vecino convento de la Merced $^{45}$, la cual, según consta en las constituciones del hospital, habría de ser trasladada a este en el caso de que los frailes no celebrasen los oficios religiosos de acuerdo con lo dispuesto por el fundador o

$39 \ll \mathrm{Y}$ queremos y ordenamos que en este dicho nuestro Hospital se reciban pobres enfermos de tales enfermedades que sean y puedan ser curables»: Eugenio FONTANEDA PÉREZ, El Hospital de la Piedad... [ver n. 1], p. 442.

40 José Manuel NIETO SORIA, Los proyectos de reforma... [ver n. 10], p. 509.

41 María José Díez Hermano, Escribir para administrar... [ver n. 3], p. 49.

42 Eugenio Fontaneda PÉREZ, El Hospital de la Piedad... [ver n. 1], p. 449.

43 Ibid., p. 433.

44 María del Pilar RÁBADE OBRADÓ, Mecenazgo religioso y estrategias familiares en la Segovia del siglo XV: Diego Arias de Avila y el Hospital de San Antonio, en Anuario de Estudios Medievales, 32/2 (2002), pp. 926, 939 y 946-947.

45 Ibid., p. 943. 
se negasen a dar sepultura en su cementerio a los pobres fallecidos en el hospital. El traslado, el cual habría de realizarse a costa del convento, culpable del mismo, conllevaría a su vez la fundación de «otra universidad de frayres e rreligiosos e clérigos», encargados, a partir de ese momento, del servicio de las dos capellanías perpetuas de la capilla funeraria y del entierro de los pobres del hospital ${ }^{46}$.

Similar habría sido el caso del hospital de San Hermenegildo en Sevilla, comúnmente conocido como el Hospital de los Heridos u Hospital del Cardenal, fundado en Sevilla el 16 de noviembre de 1453 por el cardenal Juan de Cervantes, junto al convento de San Leandro ${ }^{47}$. La labor asistencial de Cervantes, equiparable a la de Barrientos, no solo respondería a las exigencias sociales bajomedievales por las cuales todo cristiano estaba obligado a la limosna, en especial, reyes, nobles y prelados de alta jerarquía, sino también a la propia iniciativa del hombre moderno que llevó a cabo fundaciones para alcanzar el beneficio de la divinidad ${ }^{48}$.

Cabe asimismo mencionar el hospital de San Juan Bautista en Toledo, fundado en 1540 por Juan Pardo de Tavera. A pesar de no haber sido originariamente concebido por su fundador como su lugar de sepultura, en su testamento, el cardenal Tavera ordenó finalmente ser enterrado en la capilla de su hospital ${ }^{49}$. Fuera del territorio hispano, estas iniciativas no fueron extrañas como muestra la decisión de Rainaldo Brancacci de ser enterrado en su hospital, dedicado a Sant'Angelo a Nilo, en Nápoles ${ }^{50}$.

46 Justino Matute y GaVIRIA, Adiciones y correcciones a Los Hijos de Sevilla ilustres en santidad, letras, armas, artes y dignidad de D. Fermín Arana de Varflora, Sevilla, 1886, pp. 69-72; Alonso SÁNCHEZ GORDILLO, Memorial sumario de los arzobispos de Sevilla y otras obras, ed. José Sánchez Herrero, Sevilla, 2003, p. 18; A.M.T.: Testamento del Cardenal Cervantes, en Boletín de la Real Academia Sevillana de Buenas Letras, 41 (1924), pp. 121-131; Juan Manuel LOZANO, El testamento del Cardenal fuan de Cervantes, en Lora del Río. Feria y Fiestas Populares, 1987, pp. 58-59; María del Pilar RÁBADE OBRADÓ, Religiosidad y práctica cristiana en la familia Arias de Avila, en Ángel GALINDO GARCÍA (ed.), Arias Dávila: Obispo y Mecenas. Segovia en el siglo XV, Salamanca, 1998, pp. 206-208; María Blanca LóPEZ DíAZ, Las Artes en el siglo XV: el mecenazgo de los Arias Dávila, en Ángel GALINDO García (ed.), Arias Dávila: Obispo y Mecenas. Segovia en el siglo XV, Salamanca, 1998, pp. 278-284; María del Pilar RÁBADE OBRADÓ, Mecenazgo religioso y estrategias familiares... [ver n. 44], pp. 945946.

47 Alejandra PIÑEYRÚA, Caridad cristiana, asistencia social y poder politico: las instituciones hospitalarias en España (siglos XIII al XVI), en María Estela GONZÁLEZ DE FAUVE (ed.), Ciencia, poder e ideología. El saber y el hacer en la evolución de la medicina española (siglos XIV-XVIII), Buenos Aires, 2001, p. 90.

48 Ibid., p. 91.

49 Javier CaSTÁn LANASPa, A propósito del testamento del Cardenal Tavera, en Boletín del Seminario de Estudios de Arte y Arqueología, 59 (1993), pp. 365-378, pp. 365, 367 y 373.

50 Vicenzo RegINA, Le Chiese di Napoli. Viaggio indimenticabile attraverso la storia artística, architettonica, letteraria, civile e spirituale della Napoli Sacra, Roma, 1995, p. 109; John T. PAOLETTI y Gary M. RADKE, Arte en la Italia del Renacimiento, Madrid, 2002, p. 190. 


\section{III.1. La capilla funeraria de Lope de Barrientos}

Los padres de Lope de Barrientos fueron enterrados en la capilla de las Once Mil Vírgenes del convento de San Andrés de Medina del Campo, en cuyo altar, según deja estipulado el propio Barrientos en su testamento, habrían de decirse diariamente dos misas rezadas tanto por su alma, como por la de sus progenitores ${ }^{51}$. Asimismo, permite que en dicha capilla sean sepultados los visitadores de su hospital, y sus «fijos [...], e nietos, e todos los otros que dellos desçendieren», siempre y cuando «non fagan sepulturas altas saluo llanas, con sus lanchas de piedra labradas yguales con el suelo [...] a la entrada de la dicha capilla e a los lados de los vultos de los dichos nuestros padre e madre, por tal manera que non sea ninguno sepultado entre el altar e los dichos vultos» ${ }^{52}$.

Frente a lo que, quizás, cabría esperar, Lope de Barrientos no mandó ser enterrado en la capilla familiar, sino que prefirió fundar la suya propia en el hospital de Santa María de la Piedad. Lamentablemente, apenas se conservan restos de dicho espacio funerario, entre los que destaca, sin lugar a dudas, la estatua orante del prelado, a modo de «retrato vivo», realizada en alabastro -acompañado de un perro esculpido en el mismo material- mandada colocar por el propio Barrientos «en medio de la dicha nuestra capilla del dicho nuestro ospital» ${ }^{53}$ (fig. 2). La extraordinaria calidad de la misma nos permite hacernos una leve idea de la magnificencia del conjunto. Esta imagen, atribuida a Egas Cueman, estaría ya terminada en 1469 -año en el que fallece nuestro prelado-, puesto que aparece mencionada en su testamento en 1454. De hecho, según los últimos estudios realizados en torno a la imagen de Barrientos, esta habría sido realizada entre 1447 y $1454^{54}$, cronología que intentaremos precisar más adelante.

Las escasas descripciones conservadas de la capilla nos aportan relevantes datos acerca de su estructura arquitectónica, y, muy especialmente, de su techumbre, así como de la importante presencia de decoración heráldica, existente también en el patio del hospital (fig. 3). Gracias al valioso testimonio de José Ma-

51 Posiblemente, las imágenes sepulcrales de sus padres fuesen también obra de Egas Cueman: David CHaO CaStro, Egas Cueman en Castilla y el desarrollo de la tipología sepulcral con imagen orante, en Rogier van der Weyden y España. Actas del Congreso Internacional, Madrid, 2015, pp. 4356, pp. 46-47; Paloma CUENCA MUÑOZ, El legado testamentario... [ver n. 2], pp. 312-313.

52 Paloma CuenCa MuÑoz, El legado testamentario... [ver n. 2], p. 314.

53 Ibid., p. 309; Francesca ESPAÑOL BERTRÁN, Encuadres arquitectónicos para la muerte: de lo ornamental a lo representativo. Una aproximación a los proyectos funerarios del tardogótico bispano, en Codex Aquilarensis, 31 (2015), pp. 93-120, pp. 110-112.

54 Antonio SÁNCHEZ DEL BARRIO (ed.), Simón Ruiz, mercader, banquero y fundador, catálogo de la exposición, Medina del Campo, 2016, cat. 29, p. 214. 

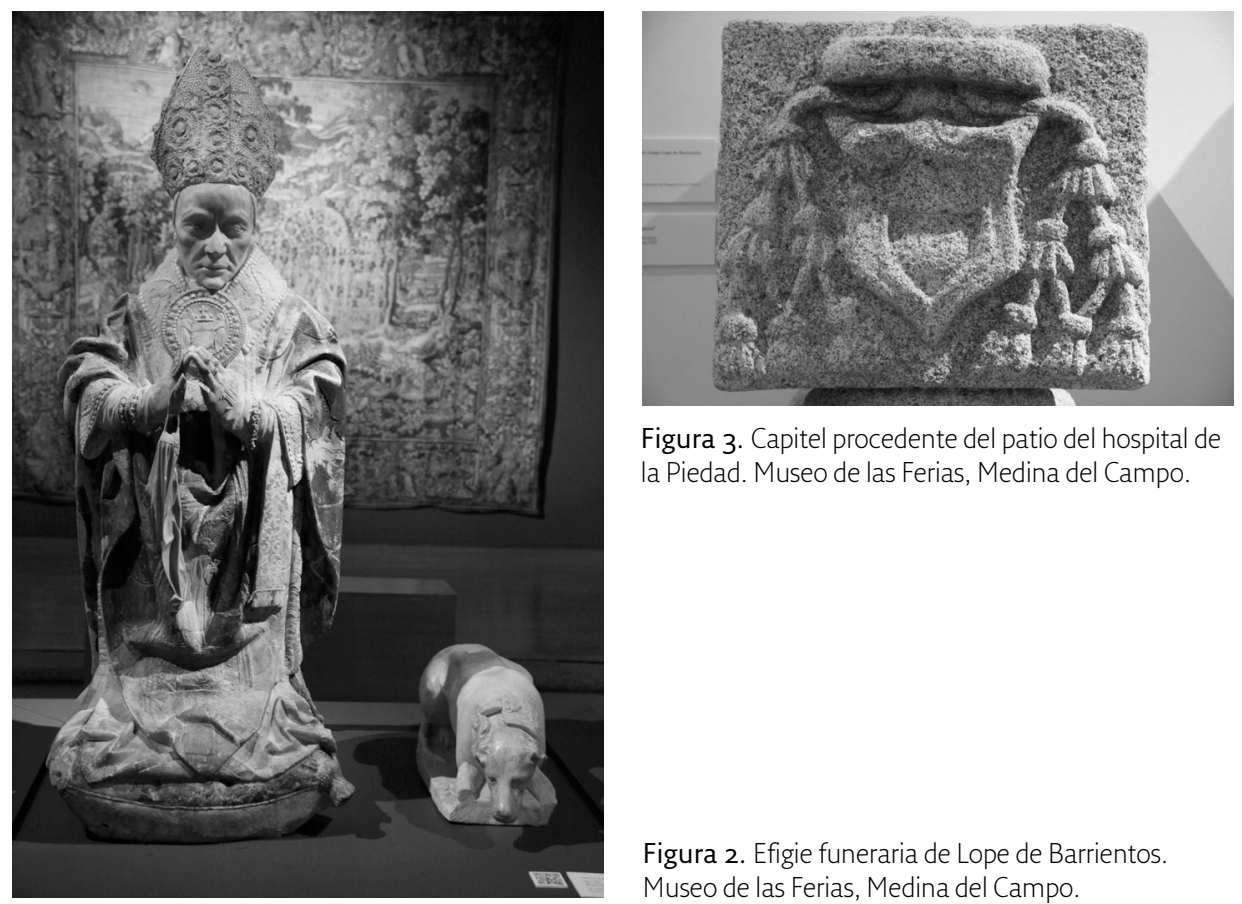

Figura 3. Capitel procedente del patio del hospital de la Piedad. Museo de las Ferias, Medina del Campo.

Figura 2. Efigie funeraria de Lope de Barrientos. Museo de las Ferias, Medina del Campo.

ría Quadrado, sabemos que la imagen orante de Barrientos se colocó «bajo una cúpula artesonada de estrellas de gusto arábigo» y que una inscripción de friso recordaba los «títulos y blasones» del obispo, exaltando, a la vez, su condición de fundador del linaje de Barrientos, un honor que le fue concedido el 11 de junio de 1454 por el príncipe Enrique, futuro Enrique IV (1454-1474), como recompensa por su lealtad ${ }^{55}$. Una descripción similar nos la ofrece a principios del siglo XX Javier Martí y Monsó, quien señala que la capilla del hospital, la cual había sido ya desmantelada, conservaba aún algunos arcos ojivales, así como la techumbre del presbiterio «de madera labrada, con exornos geométricos de gusto mudéjar». El recuerdo de la fundación perduraba en «una lápida puesta en el ingreso del edificio, y en los escudos del Obispo que decoran las columnas del patio». La estatua de Barrientos se encontraba, por aquel entonces, «colocada en una hornacina á

55 José María QUAdrado, Sus monumentos y artes. Su naturaleza e historia. Valladolid, Palencia y Zamora, 1885, p. 223; Antonia RÍsQUEZ MADRID, Lope de Barrientos: promotor del linaje Barrientos de Cuenca, en Lope de Barrientos: seminario de cultura, 4 (2011), pp. 243-260. 
la parte del Evangelio» ${ }^{56}$. Allí permaneció hasta, aproximadamente, 1860, año en el que se trasladó a un nicho en la pared. Al abrir la sepultura bajo la estatua se pudo comprobar que esta estaba vacía, lo que hace pensar que o bien el cuerpo de Barrientos fue trasladado antes de dicha fecha, o bien nunca llegó a Medina del Campo ${ }^{57}$.

La elección de una armadura de madera con decoración de lazo como cubierta de la capilla funeraria del obispo, recordaría a otras construcciones castellanas del siglo XV, estudiadas por Juan Carlos Ruiz Souza ${ }^{58}$. Se trataría, por lo tanto, de una estructura que remitiría a la influencia de la arquitectura islámica en territorio cristiano en el siglo XV, y que respondería al proceso de «privatización de presbiterios» con carácter funerario ${ }^{59}$. Por otro lado, la abundante presencia de motivos heráldicos tanto en la capilla como en la propia efigie del prelado sería una muestra más de las altas cotas que la utilización de la heráldica con fines propagandísticos alcanzó a lo largo de la segunda mitad del siglo $\mathrm{XV}^{60}$. El deseo de Lope de Barrientos de dejar memoria de su linaje, así como de su condición como fundador del mismo, quedó también plasmado de manera evidente en el medallón, de excesivas dimensiones, que decora su pecho y que alberga un escudo que, en origen, habría lucido las armas del obispo, las cuales se repiten en la parte posterior del cuello de la casulla (fig. 4$)^{61}$. Si bien desconocemos la fecha exacta

56 José MARTí y MONSÓ, Estudios histórico-artísticos relativos principalmente a Valladolid basados en la investigación de diversos archivos, Valladolid-Madrid, 1898-1901, pp. 305-306.

57 En la capilla mayor de la catedral de Cuenca se conserva una lápida sepulcral atribuida a Lope de Barrientos, con el siguiente epitafio en latín, parcialmente conservado: $\ll \mathrm{Di}<\mathrm{s}>$ rupisti, $\mathrm{D}($ omi $)$ ne, vincula mea. / Tibi sacrificab[o host]iam laudis, et nomen $\mathrm{D}(o m i) \mathrm{n}(i)$ in[voc]abo. Christus vincit, / Christus regn $<\mathrm{a}>\mathrm{t}$, Christus imp $(e r)$ at, Christus ab/o(mn)i malo me defe $(n)$ dat. Amen. AD t $(e m)$ $\mathrm{p}(u)$ s hic iacet depositus usque consumat[ionem]. Lup $(u) \mathrm{s} \mathrm{m}(i h i)$ nome $(n)$, eccle $(e s)$ ie po $(n)$ tifex huius»: Mateo LÓPEZ Y BAENA, Memorias históricas de Cuenca y su obispado, CSIC, Ayuntamiento de Cuenca, Cuenca, 1949, vol. I, p. 231; José Manuel CAÑas Reíllo, Epitafio del obispo Lope de Barrientos, ca. 1469, en Corpus epigráfico conquense, 2010, sin paginar; Lorne CAMPBELL y Juan José PÉrez Preciado, Egas Cueman... [ver n. 34], p. 166.

58 Juan Carlos RUIZ SOUZA, La planta centralizada en la Castilla bajomedieval: entre la tradición martirial y la qubba islámica. Un nuevo capítulo de particularismo bispano, en Anuario del Departamento de Historia y Teoría del Arte, 8 (2001), pp. 9-36, pp. 9-10 y 23-24; Juan Carlos RUIZ SouZA, Castilla y la liberalidad de las artes en el siglo XV. La aceptación de la berencia de Al-Andalus: de la realidad material a los fundamentos teóricos, en Anales de Historia del Arte, 22 (2012), pp. 123-161, pp. 143-144.

59 Juan Carlos RuIZ SouzA, Castilla y la liberalidad de las artes... [ver n. 58], pp. 143-144.

60 Ibid., p. 127.

61 HERNÁNDEZ DE MENDOZA, Libro de armas y nobleza de España, RAH 9/5541, fol. CIIIIr; María Isabel GARCÍA-MONGE CARRETERO, Estudio y edición crítica, 14; José Ignacio ORTEGa CERVIGÓN, La acción política y la proyección señorial de la nobleza territorial en el obispado de Cuenca durante la Baja 


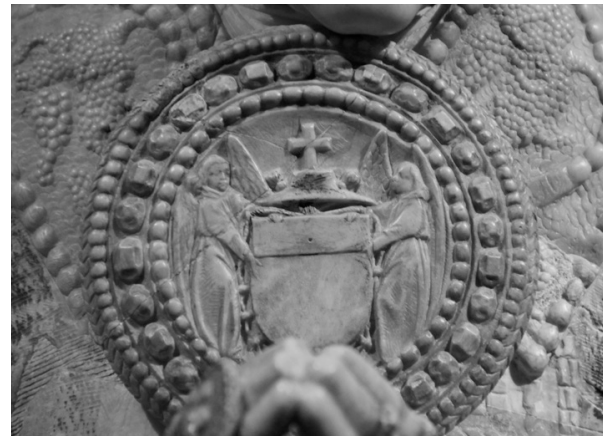

Figura 4. Detalle del medallón. Efigie funeraria de Lope de Barrientos. Museo de las Ferias, Medina del Campo.

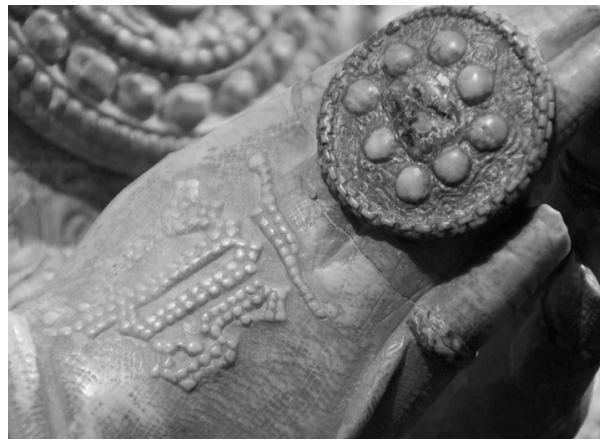

Figura 5. Guantes. Efigie funeraria de Lope de Barrientos. Museo de las Ferias, Medina del Campo.

de ejecución de la efigie funeraria, esta pudo haber sido realizada en torno a 1454 , y, quizás, encargada entre el 11 de junio de 1454, momento en el que el heredero al trono concedió al prelado el título de fundador del linaje Barrientos, y el 17 de noviembre de ese mismo año, día en el que el obispo dictó su testamento en la villa de Medina del Campo.

La estatua funeraria de Barrientos viste casulla ${ }^{62}$ y guantes ${ }^{63}$, decorados estos últimos con una inscripción, realizada empleando la técnica de la scrittura a punti, en la cual se puede leer $\ll i \bar{h} s / / x \overline{\mathrm{p}} \mathrm{s}{ }^{64}$ (fig. 5). No por ello aparece representado como un oficiante, sino arrodillado, en una clara actitud orante, ante el Sagrado Sacramento, y, por lo tanto, en una postura que, según David Chao Castro, emularía los Nueve modos de orar de santo Domingo ${ }^{65}$. El modelo de efigie funeraria elegido por Barrientos recuerda, a su vez, a la estatua orante de Pedro I de Castilla (1350-1369), conservada en el Museo Arqueológico Nacional de Madrid y procedente del desaparecido convento de Santo Domingo el Real

Edad Media, tesis doctoral, Universidad Complutense de Madrid, 2006, pp. 206-209; Juan Carlos Moreno Moreno, Linajes de Medina del Campo... [ver n. 6], pp. 151-153; Antonia RISQUEZ, Lope de Barrientos... [ver n. 55], pp. 243-260, pp. 247-248 y 254-256.

62 Marta CENDÓN FERNÁNDEZ, La indumentaria episcopal como reflejo de poder en la escultura funeraria bajomedieval, en Estudios in Memoriam del Prof. Dr. Fernando Galván Freile, León, 2011, pp. 101120, pp. 108-109 y 114-115.

63 Barrientos parece portar un limosnero en su mano izquierda.

64 Francisco Javier MOLINA DE LA TORRE, Epigrafía medieval y moderna... [ver n. 7], p. 111, nota 80 y p. 457.

65 David Chao Castro, Egas Cueman en Castilla... [ver n. 51], pp. 46-47. 
de Madrid (fig. 6). Esta imagen ha sido fechada por David Chao Castro y David Nogales Rincón hacia $1446^{66}$, datación que haría de esta obra una de las imágenes funerarias orantes más antiguas conservadas en Castilla. Si bien la tipología parece ser de origen transpirenaico ${ }^{67}$, lo más probable es que el principal referente artístico de Lope de Barrientos -prelado que permaneció siempre próximo a la corte y que, en principio, no consta documentalmente que llegase a traspasar los límites geográficos de los territorios hispanos- fuese, precisamente, la del mencionado monarca. De hecho, Barrientos no solo fue prior del convento madrileño en 1431, es decir, durante el largo priorato de sor Constanza de Castilla (†1478), nieta de Pedro I y principal responsable del encargo de la estatua de su abuelo, sino que, además, en 1454 intervino a favor de la citada superiora, a petición de la Corona, con motivo de las quejas del arzobispado de Toledo ante el gasto desorbitado aprobado por Constanza y destinado a la ampliación y acondicionamiento tanto del convento como de sus propias estancias ${ }^{68}$. La presencia del prelado en Santo Domingo el Real de Madrid ha llevado, incluso, a algunos autores, a plantear la posibilidad de que este llegase a residir durante un tiempo en el mismo ${ }^{69}$.

Por su parte, Marta Cendón ha señalado la excepcionalidad de la tipología funeraria elegida por Barrientos para su sepulcro, puesto que no resulta habitual entre los prelados en Castilla a finales de la Edad Media ${ }^{70}$. Desde mi punto de vista, Barrientos habría encargado su efigie funeraria a imitación de la de Pedro I de Castilla, movido tanto por el creciente culto a la Eucaristía, documentado a mediados del siglo XV, como por la novedad del diseño escultórico -puesto que la tipología funeraria, como recuerdan Francesca Español Bertrán y David Chao Castro, ha de ser puesta en relación con el propio interés de los comitentes ${ }^{71}$, y,

66 David Chao Castro, La estatua sepulcral de Pedro I: ¿la importación de un modelo transpirenaico?, en Concepción Cosmen, María Victoria Herráez y María Pellón GómeZ-CalCERRADA, El intercambio artístico entre los reinos hispanos y las cortes europeas en la Baja Edad Media, León, 2009, pp. 103-125, p. 112; David NOGALES RINCÓN, La representación religiosa de la monarquía castellano-leonesa: la capilla real (1252-1504), tesis doctoral, Universidad Complutense de Madrid, 2009, vol. II, p. 1494.

67 David Chao Castro, La estatua sepulcral de Pedro I... [ver n. 66], pp. 117-120.

68 Juan Ramón Romero FernándeZ-Pacheco, Santo Domingo el Real de Madrid. Ordenación económica de un señorío conventual durante la baja edad media (1219-1530), Salamanca, 2007, pp. 128 y 256.

69 Luis G. Alonso-Getino, Centenario y Cartulario de nuestra Comunicad, en Ciencia Tomista, 59 (1919), pp. 129-152, p. 137.

70 David Chao Castro, La estatua sepulcral de Pedro I... [ver n. 66], p. 112; David Nogales RINCÓN, La representación religiosa..., vol. II [ver n. 66], p. 1494.

71 Francesca ESPAÑOL BERTRÁN, Encuadres arquitectónicos para la muerte [ver n. 53], p. 116; David ChaO Castro, Egas Cueman en Castilla... [ver n. 65], p. 44. 


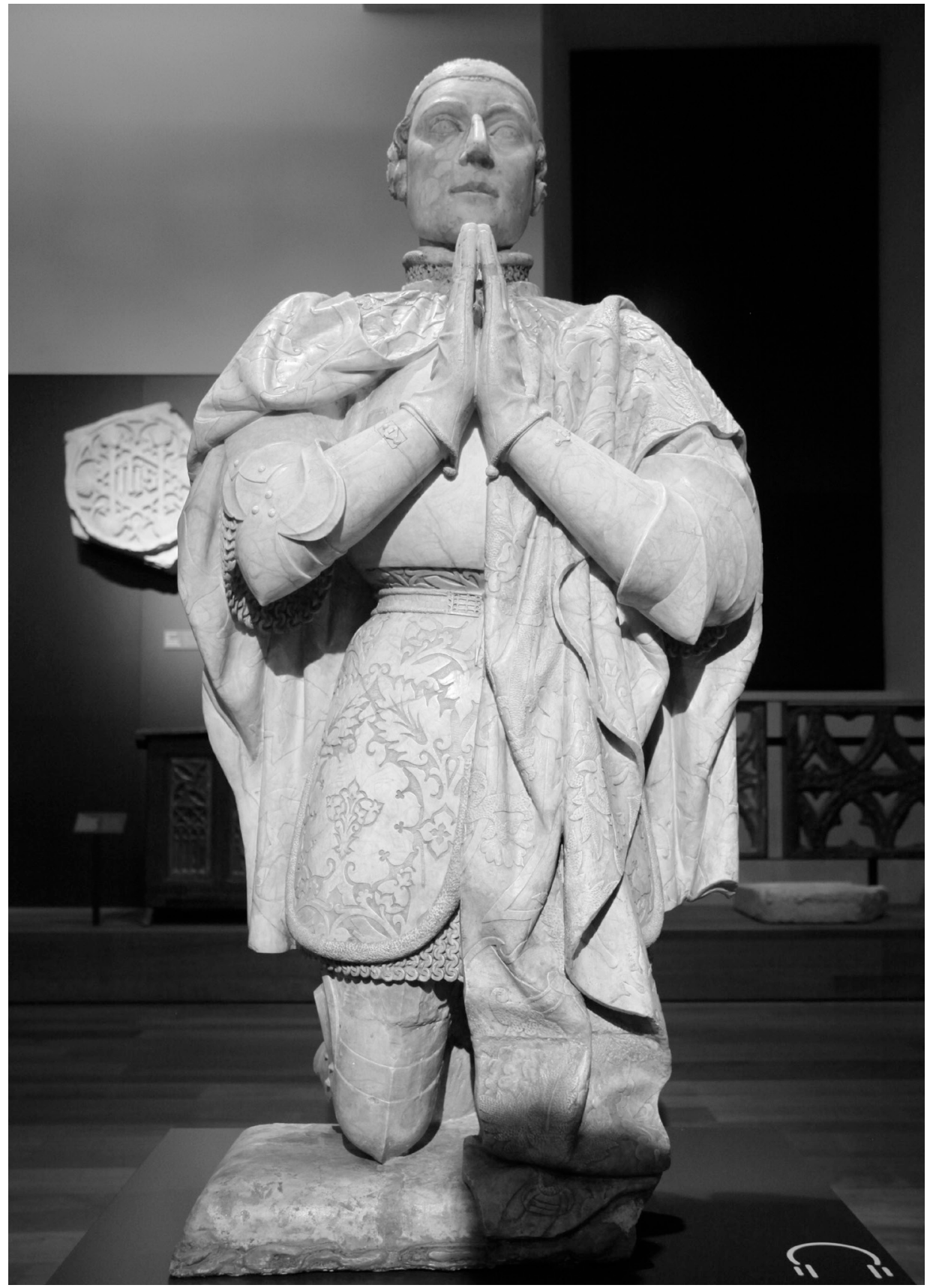

Figura 6. Estatua orante de Pedro I de Castilla. Museo Arqueológico Nacional, Madrid. 
por lo tanto, no exclusivamente del artífice-, el cual habría garantizado tanto la originalidad y exclusividad de su propio proyecto funerario, como su fama póstuma. Recordemos, además, que Barrientos habría encargado su efigie funeraria $-\mathrm{y}$, quizás, también las de sus progenitores- a uno de los más destacados escultores activos por aquellos años en Castilla, como lo fue Egas Cueman ${ }^{72}$, lo que aseguraba la calidad y magnificencia de la obra, al mismo tiempo que situaba al obispo a la cabeza de la vanguardia artística.

En el estolón de la casulla están bordados sobre fondo de oro seis ángeles que portan los instrumentos de la Pasión o arma Christi ${ }^{73}$. El que se encuentra detrás de las manos del prelado lleva el flagelo y la columna; el que está debajo, la lanza y los tres clavos; y el de la parte inferior, las tenazas. En la espalda, el ángel superior porta el martillo y la escalera; el siguiente, la cruz; y el inferior, la corona de espinas y lo que, según han apuntado Lorne Campbell y Juan José Pérez Preciado, parece ser la caña (figs. 7 y 8$)^{74}$.

A principios del siglo XIV, los arma Christi fueron empleados, no como un recordatorio del sufrimiento experimentado por Cristo durante la Pasión, sino como una representación figurativa de su victoria sobre el Demonio y el Mal. En un principio estaban limitados a aquellos instrumentos estrechamente relacionados con la Crucifixión, como, por ejemplo, la corona de espinas, la lanza, la cruz y los clavos. Sin embargo, desde la segunda mitad del siglo XIV en adelante, la cantidad de arma Christi aumentó hasta treinta y cinco, enriqueciéndose, al mismo tiempo, su significado metafórico y devocional. En consecuencia, a finales de la Edad Media, estas imágenes no harían referencia tanto a la Resurrección de

72 David Chao Castro, Egas Cueman en Castilla... [ver n. 65], pp. 44-45; Fernando VILLASEÑor Sebastián, The Artistic Promotion of Lope de Barrientos, Bishop of Segovia, Avila and Cuenca, en Obispos y catedrales. Arte en la Castilla bajomedieval, Berna, 2018, pp. 183-220, pp. 251-216.

73 Felipe Pereda y Cynthia Robinson han incidido en el significado tanto funerario como eucarístico que los arma Christi adoptaron durante los siglos XIV y XV. Asimismo, cabe señalar que, en el MS 6539 de la Biblioteca Nacional de España, fechado en el siglo XV, la oración Culter qui circuncidisti enumera los poderes salvíficos de cada uno de los arma Christi: Alfred CoRDOLIANI, Les manuscrits du comput ecclésiastique des bibliothèques de Madrid (2ème série), en Hispania Sacra, VIII, 15 (1955), pp. 177-208, p. 182; Inventario general de manuscritos de la Biblioteca Nacional, tomo XI (5700 a 7000), Madrid, p. 210; Felipe PEREDA, Las imágenes de la Discordia. Política y poética de la imagen Sagrada en la España del 400, Madrid, 2007, pp. 44-47; Cynthia ROBINSON, Imagining the Passion in a Multiconfessional Castile. The Virgin, Christ, Devotions, and Images in the Fourteenth and Fifteenth Centuries, Pennsylvania, 2013, pp. 326 y 329; David CHAO CASTRO, Egas Cueman en Castilla... [ver n. 65], pp. 43-56, p. 46; Éric PALAZZO, Peindre c'est prier. Antbropologie de la prière chrétienne, París, 2016, pp. 129-132.

74 Lorne CAMPBell y Juan José PÉrez Preciado, Egas Cueman... [ver n. 48], pp. 166-170. 


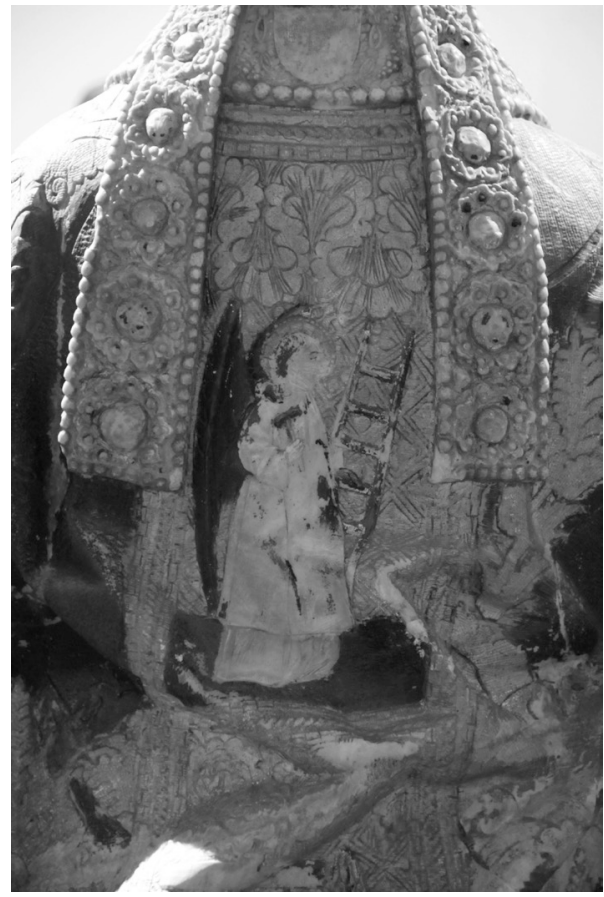

Figura 7. Ángeles con arma Christi. Efigie funeraria de Lope de Barrientos. Museo de las Ferias, Medina del Campo.

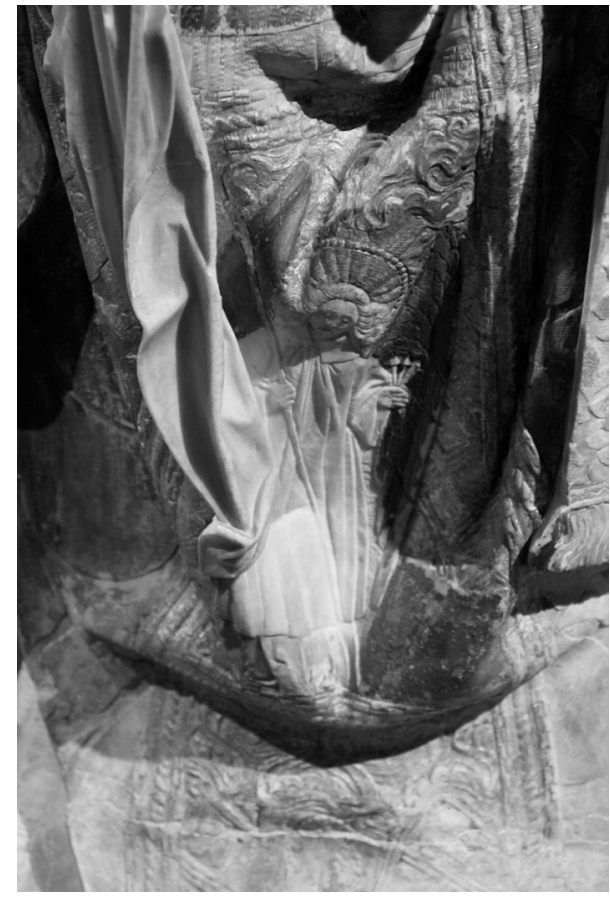

Figura 8. Ángel con arma Christi. Efigie funeraria de Lope de Barrientos. Museo de las Ferias, Medina del Campo.

Cristo, como a su sufrimiento y su naturaleza humana ${ }^{75}$. La Pasión de Cristo es, en efecto, rememorada en el testamento de Lope de Barrientos, en aquellos momentos en los que ruega por la salvación de su alma ${ }^{76}$, para lo cual, recordemos, que el propio obispo asegura desear fundar su hospital de la Piedad.

La necesidad de que los religiosos experimentasen, y sufriesen, en sus propios cuerpos, la Pasión de Cristo, para así fortalecer sus almas y, con ello, hacer frente a todas las batallas espirituales que habrían de lidiar a lo largo de sus vidas, había sido ya mencionada por Enrique Susón (ca. 1300-1366) en su Diálogo de la

75 Marta Cendón Fernández, El obispo ante la muerte en la Castilla de los Trastámara, en Archivo ibero-americano, LXVII, 258 (2007), pp. 677-708, p. 704; Richard G. NEWHAUSER y Arthur J. Russell, Mapping Virtual Pilgrimage in an Early Fifteenth-Century Arma Christi Roll, en Lisa H. Cooper y Andrea Denny-Brown (eds.), The Arma Christi in Medieval and Early Modern Material Culture, Franham-Burlington, 2014, pp. 83-112, pp. 86-87.

76 Paloma CuenCa MUÑoz, El legado testamentario... [ver n. 2], pp. 308-310. 
Eterna Sabiduría ${ }^{77}$, obra que seguramente Barrientos conoció, al tratarse de un texto recuperado en pleno siglo XV en ambientes reformistas ${ }^{78}$. En ella, el dominico mantiene un diálogo con Cristo, quien le da una serie de consejos para llegar a la «magestad de su divinidad» que Barrientos pudo haber tenido presentes a la hora de diseñar la imagen que de sí mismo deseaba legar a la posteridad, y que habría de garantizarle la salvación de su alma y, con ello, la vida eterna:

Nadie puede llegar a la magestad de mi divinidad ni a mi insólita dulzura, si antes no prueba la amargura de mi humanidad. Cuanto más alto intenta uno subir sin ésta, tanto más bajo cae. Mi humanidad es el camino que se debe seguir; mi pasión es la puerta por donde debe entrar todo el que quiera conseguir lo que tú deseas. Sacúdete la cobardía de tu corazón y entra conmigo en el campo de batalla donde se baten los caballeros, pues no está bien que el siervo viva relajadamente mientras su señor se deja la piel en primera línea ${ }^{79}$.

De mayor relevancia resultan las palabas que Cristo le dirige a Susón cuando le indica que desea vestirle y fortificarle con sus propias armas, es decir, con los arma Christi, los mismos que cubren el cuerpo de Barrientos: «Ahora quiero revestirte y fortificarte con mis armas, pues es preciso que, al igual que Yo, experimentes toda mi pasión en proporción a tus fuerzas» ${ }^{80}$.

Esta visión mística adquiere un sentido escatológico, que encajaría perfectamente en el ámbito funerario para el cual fue concebida la imagen orante de Barrientos, cuando Cristo finalmente invita a su siervo a recorrer «el penoso camino de la cruz, como alguien que va a morir y no ha de volver a tener trato con esta vida ${ }^{81}$ :

Llevarás mi pasión en tu corazón por todas partes, tan amorosamente como una madre lleva a su hijo. Tendrás que soportar muchas calumnias contra tu modo de vida religiosa, y los que viven al modo humano se burlarán de tu piedad juzgándola como demencia. Una vida de sacrificio y austeridad castigará tu cuerpo, poco acostumbrado a ello, y obtendrás como corona el desprecio de tu santo modo de vida. Luego, cuando hayas renunciado a tu voluntad, te niegues a ti mismo y te guardes libre de todas las criaturas que puedan convertirse en un

77 Marta CENDÓn FERNÁNDEZ, Obispo ante la muerte... [ver n. 75], pp. 680-681.

78 Diana LuCía Gómez-ChaCón, El Monasterio de Santa María la Real de Nieva. Reinas y Predicadores en tiempos de reforma (1392-1445), Segovia, 2016, p. 126.

79 Enrique Suso, Diálogo de la Eterna Sabiduría, Salamanca, 2002, p. 72.

80 Ibid., pp. 72-73.

81 Santa Catalina de Siena (1347-1380) incluye un mensaje similar en su oración Sobre la Pasión de Cristo: Ángel MoRTA, Obras de Santa Catalina de Siena. El Diálogo, Madrid, 1955, p. 605. 
obstáculo para tu salvación eterna, serás llevado conmigo y recorrerás el penoso camino de la cruz, como alguien que va a morir y no ha de volver a tener trato con esta vida ${ }^{82}$.

Teniendo en cuenta que la escultura orante de Barrientos, vestida con los arma Christi, fue destinada, desde su concepción, a la capilla funeraria del prelado en el hospital de la Piedad en Medina del Campo, cabe señalar que, como ha apuntado Adam J. Davis, algunos exempla medievales llegaron a establecer una comparativa entre el sufrimiento de los menesterosos y el experimentado por Cristo en su Pasión ${ }^{83}$. De hecho, a lo largo de la Edad Media existió una estrecha relación entre las obras de caridad y el sacrificio eucarístico ${ }^{84}$. Por lo tanto, la promoción de centros hospitalarios habría sido considerada una forma más de imitatio Christi.

Si recordamos las palabras que Barrientos dirige a Nicolás V en su súplica de 1447 , en la que solicita permiso al pontífice para fundar su hospital, los motivos que le llevan a ello son los anteriormente indicados: «de salute propia recogitant et cupiens terrena en caelestia et transitoria in aeterna commutare $\gg^{85}$. Esta declaración, que ha pasado desapercibida, resulta de suma importancia al contener las razones expresadas por el propio Barrientos para fundar su hospital. Tampoco se ha señalado la relevancia de que el obispo medinense tomase como autoridad las palabras de san Pablo, en 2 Co 4, 17-18. Pasaje en el que se incide nuevamente en la importancia del ministerio apostólico, la fuerza de Dios y la debilidad de su siervo:

En efecto, la leve tribulación de un momento nos procura, sobre toda medida, un pesado caudal de gloria eterna, a cuantos no ponemos nuestros ojos en las cosas visibles, sino en las invisibles; pues las cosas visibles son pasajeras, mas las invisibles son eternas.

Este mismo texto es comentado por san Agustín, autor de referencia para la Orden de Predicadores, quien las dota de un carácter nuevamente escatológico

82 Enrique SuSO, Diálogo... [ver n. 79], p. 73.

83 Adam J. DAVIS, Hospitals, Charity, and the Culture of Compassion in the Twelfth and Thirteenth Centuries, en Approaches to Poverty in Medieval Europe. Complexities, Contradictions, Transformations, c. 1100-1500, Turnhout, 2016, pp. 23-46, p. 36.

84 Ibid., 36-37 y 41.

85 Vicente Beltrán de Heredia, Bulario... tomo III [ver n. 15], pp. 9-10; María José DíEz HerMANO, Escribir para administrar... [ver n. 3], p. 49, nota 6; Ángel MARTÍNEZ CASADO, Lope de Barrientos... [ver n. 5], p. 87. 
que, sin lugar a dudas, Barrientos habría tenido presente al redactar su súplica, tras haber alcanzado su «sexta edad»:

La vida del hombre viejo, que se recorre según la carne desde la creación del tiempo, se concluye en la sexta edad con la vejez o senectud. En esta vejez del género humano, como he dicho, nuestro Señor ha venido a nosotros como creador y redentor, para que, por así decirlo, muriendo el hombre viejo, constituye en sí al hombre nuevo al que, purificado del pecado terreno, iba a transportar a los reinos celestiales [...] porque el exterior es el hombre viejo, y el interior el nuevo, el decir del Apóstol: Y aunque el hombre exterior se corrompe, pero el interior se renueva de día en día (ya que al hombre exterior pertenecen todas las cosas visibles, a las cuales renuncia la disciplina cristiana), con la más absoluta razón el Señor llegó al pozo a la hora sexta, es decir, a medio día, cuando ya este sol visible comienza a declinar hacia el ocaso, puesto que también para nosotros, llamados por Cristo, comienza a disminuir el deleite de las cosas visibles, para que el hombre interior recreado por el amor de las cosas invisibles se convierta a la luz del interior, que nunca muere, según la doctrina apostólica: sin poner la mira en lo que se ve, sino en lo que no se ve, porque lo que se ve es temporal, y lo que no se ve es eterno ${ }^{86}$.

\section{III.2. Objetos donados por Barrientos al hospital de la Piedad}

Asimismo, son varios los objetos donados por nuestro prelado a su hospital, actualmente custodiados en el Museo de las Ferias. En su testamento, Barrientos cita «el báculo de sant Antón que nós tenemos guarnido de plata sobredorado», el cual manda que sea colocado «en el logar más conueniente que se fallare ${ }^{87}$ (fig. 9). Esta pieza, realizada en madera de ébano y con empuñadura y abrazaderas de plata sobredorada, decoradas con los escudos y nombres de Gregorio XI (1370-1378), Benedicto XIII (1378-1394) y Clemente VII (1394-1423) ${ }^{88}$, habría sido elaborada en Avignon, en fecha anterior a $1378^{89}$ (fig. 10). Ha conservado su funda de cuero repujado, ornamentada con motivos vegetales, la cual podría haber sido encargada en Castilla por el propio Barrientos, en fecha cercana a su

86 San Agustín, Ochenta y tres cuestiones diversas, cuestión 64, en San Agustín, Obras completas de san Agustín. XL. Escritos varios (2. ${ }^{\circ}$ ), ed. Teodoro C. Madrid, Madrid, 1995, pp. 187-188.

87 Paloma CuenCa MuÑoz, El legado testamentario... [ver n. 2], p. 315.

88 Según Francisco Javier Molina de la Torre, «los nombres del papa y de los antipapas grabados en los arcos que forman parte del báculo del obispo Barrientos pueden remitir a una donación por parte de dichos personajes o ser una marca de propiedad». Francisco Javier MOLINA DE LA TORRE, Epigrafía medieval y moderna... [nota 9], p. 199.

89 Antonio SÁNCHEZ DEL BARRIO (ed.), Simón Ruiz... [ver n. 70], cat. 34, p. 215. 


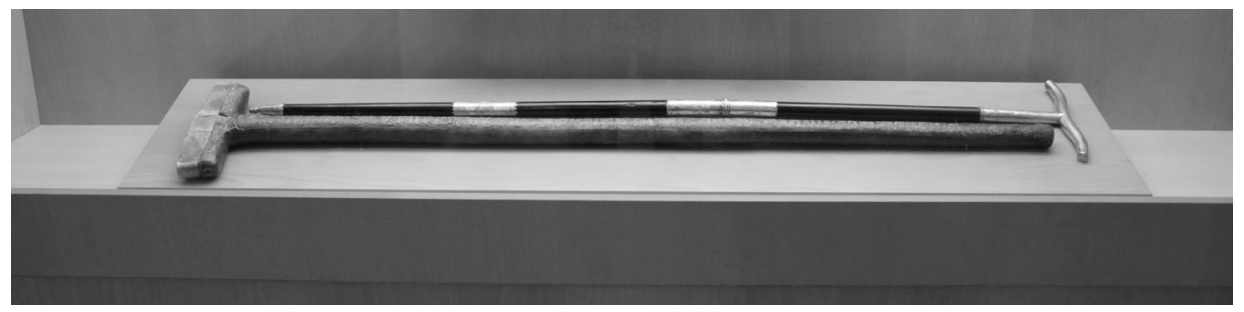

Figura 9. Báculo de san Antonio Abad. Museo de las Ferias, Medina del Campo.

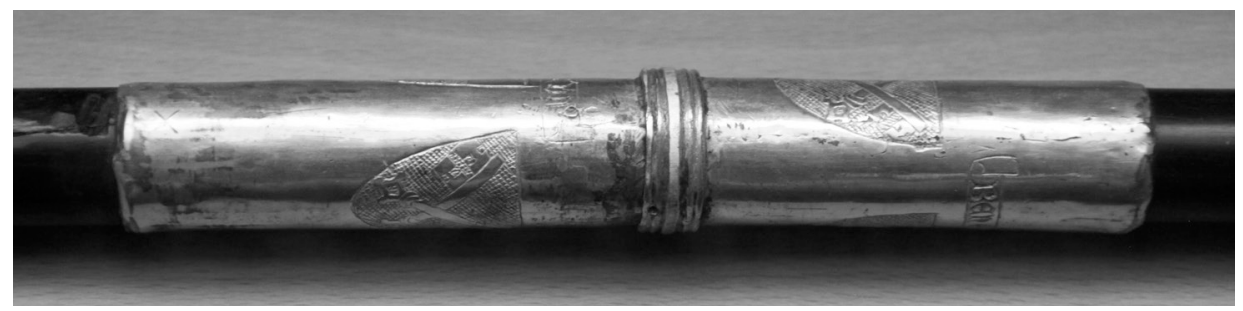

Figura 10. Báculo de san Antonio Abad. Museo de las Ferias, Medina del Campo.

muerte, y que tiene grabado un fragmento de un refrán castellano: «DE DYOS .

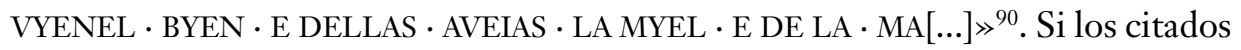
motivos heráldicos hacen alusión a los anteriores propietarios de la reliquia ${ }^{91}$, es posible que Barrientos la hubiese recibido de manos del propio Benedicto XIII con motivo de su, ya mencionada, visita a Morella en 1414 .

El hecho de que se trate de una reliquia de un santo ajeno a la Orden de Predicadores nos lleva a preguntarnos por el motivo que habría llevado a Barrientos a atesorar una reliquia de estas características y a legarla, al final de sus días, a su principal fundación, donde él mismo habría de ser sepultado, aspecto al que no se le ha prestado la debida atención. A la evidente relación de la figura de san Antonio Abad con la práctica de la asistencia hospitalaria, habría que añadir la analogía que la Orden de Predicadores habría deseado establecer, desde su fundación, con los padres del desierto, en general, y con san Antonio Abad, en particular. Alain Boureau ha señalado cómo las Vitae patrum sirvieron tanto de referente

90 Francisco Javier MOLINA DE LA TORRE, Epigrafía medieval y moderna... [ver n. 9], pp. 198 y 446-451; Manuel ARIAS y José Ignacio HERNÁNDEZ, Piezas para el recuerdo de un gran prelado, en Antonio SÁNCHEZ DEL BARRIO (coord.), La escultura de Lope de Barrientos en el Museo del Prado, Medina del Campo, 2015, p. 28.

91 Francisco Javier MOLINA DE LA TORRE, Epigrafía medieval y moderna... [ver n. 9], p. 199. 
literario como de modelo de vida a los primeros dominicos, como queda puesto de manifiesto en el Epilogus in gesta sanctorum (1245) de Barthélemy de Trente, la Leyenda dorada (ca. 1264) de Jacopo da Varazze y las Vitae fratrum (1260-1271) de Gerardo de Frachet ${ }^{92}$. Boureau subraya, a su vez, el paralelismo existente entre santo Domingo de Guzmán y san Antonio Abad. Según este autor, las biografías de ambos santos, considerados auténticos pater para sus fratres, se superpondrían. Mientras que san Antonio persiguió a los arrianos, santo Domingo se opuso a los cátaros. Ambos habrían tenido enfrentamientos violentos con el demonio y habrían tratado de proteger a sus hermanos de la tentación ${ }^{93}$. Además, las Vitae fratrum de Gerardo de Frachet, obra encargada por Humberto de Romans, quinto maestro general de la orden entre 1254 y 1263, habría tenido como principal objetivo la construcción literaria y espiritual de una nueva Tebaida, encarnada en los frailes dominicos ${ }^{94}$.

La imagen de los padres del desierto como modelo a imitar por los dominicos fue recuperada a finales del siglo XIV y principios del siglo XV por el reformador Giovanni Dominici (ca. 1356-1419). El florentino, al tratar el tema de la disciplina, recurre a los padres del desierto como ejemplo a seguir por todos sus hermanos, ya que su obediencia era tal que nunca necesitaron una Constitución que se la impusiese ${ }^{95}$. En este sentido, y teniendo en cuenta el celo reformador de Barrientos, su devoción hacia san Antonio Abad pudo haberse visto acrecentada por las similitudes entre el fundador de la Orden de Predicadores y el santo ermitaño, así como por la recuperación de la espiritualidad de la Tebaida por los primeros impulsores de la observancia dominicana ${ }^{96}$.

Otro de los objetos donados por Barrientos a su hospital fue un cáliz decorado con sus armas heráldicas (fig. 11). Uno de los medallones que decoran el nudo contiene una cruz que ha sido descrita como patada, y, por lo tanto, interpretada como un signo más de la devoción que el prelado habría sentido por san

92 Alain BoUREAU, Vitae fratrum, vitae patrum. L'ordre dominicain et le modèle des péres du désert au XIIIe siècle, en Mélanges de l'Ecole française de Rome. Moyen-Age, Temps modernes, vol. 99, n. ${ }^{\circ} 1$ (1987), pp. 79-100, pp. 84-86, 91 y 97.

93 Ibid., pp. 89-90.

94 Ibid., pp. 99-100.

95 Raymond Creytens, L'obligation des constitutions dominicaines d'après le Bx. Fean Dominici, O.P., Archivum Fratrum Praedicatorum, XXIII (1953), pp. 207-235, p. 229. Alain BOUREAU, Vitae fratrum, vitae patrum... [ver n. 106], p. 98.

96 Diana LuCÍA GÓMEZ-CHACÓN, Apariciones marianas y renovación monástica en la Castilla bajomedieval: Guadalupe y Santa María la Real de Nieva, en José Ángel GARCÍA DE CORTÁZAR y Ramón TEJA (eds.), Los monasterios medievales en sus emplazamientos: lugares de memoria de lo sagrado, Aguilar de Campoo, 2016, pp. 215-245, pp. 241-244. 


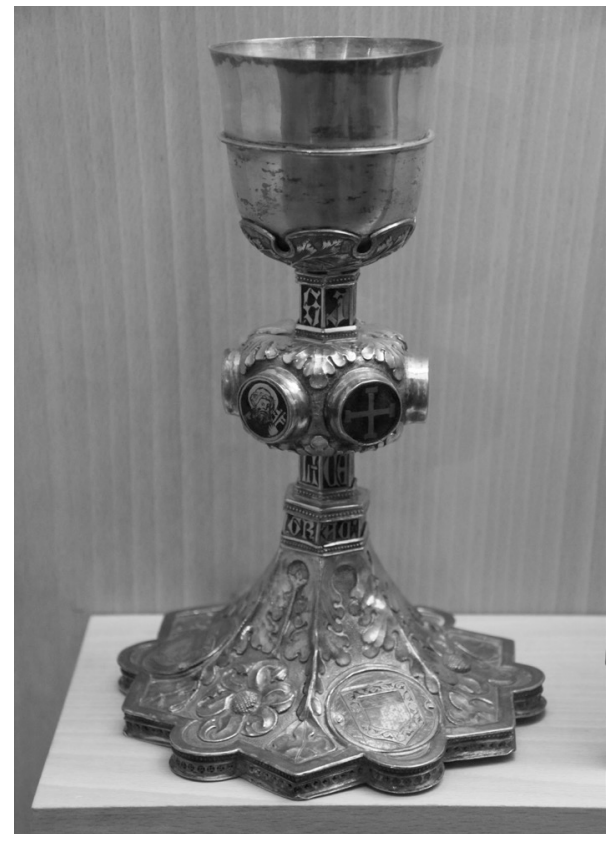

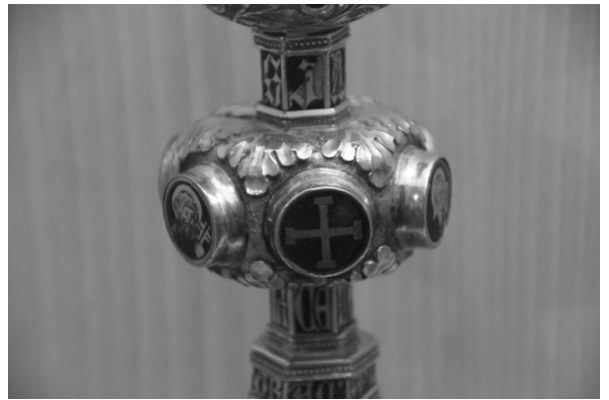

Figura 12. Detalle. Cáliz de Barrientos. Museo de las Ferias, Medina del Campo.

Figura 11. Cáliz de Barrientos. Museo de las Ferias, Medina del Campo.

Antonio $\mathrm{Abad}^{97}$. Sin embargo, una observación detenida del motivo en cuestión ha permitido constatar que en realidad se trata de una cruz potenzada y, por lo tanto, una posible alusión a la Santa Cruz, como demostraría la similitud entre la cruz que decora el cáliz de Barrientos y aquellas conservadas en la Capilla de los Condestables de Burgos, el Colegio de Santa Cruz de Valladolid y el Hospital de la Santa Cruz en Toledo ${ }^{98}$ (fig. 12).

Barrientos habría actuado una vez más movido por su devoción por la $\mathrm{Pa}$ sión de Cristo, la misma que le habría llevado a atesorar un lignum crucis, documentado en su testamento y custodiado en «una cruceta de oro... con las piedras que en ella están» ${ }^{99}$. Este resulta fácilmente relacionable con el relicario en forma

97 Manuel ARIAS, Cáliz del obispo Barrientos, en Mercaderes y Cambistas, Valladolid, p. 64; Manuel ARIAS y José Ignacio HERNÁNDEZ, Piezas para el recuerdo... [ver n. 106], p. 27.

98 Olga PÉREZ MONZÓN, La dimensión artística de las relaciones de conflicto, en José Manuel NIETO SORIA (ed.), La monarquía como conflicto en la Corona castellano-leonesa (c. 1230-1504), Madrid, p. 614. Salvador ANDRÉs ORDAX, Autoridad plástica y eco fundacional del Colegio de Santa Cruz de Valladolid, en Fernando Llamazares Rodríguez y Juan Carlos Vizuete Mendoza (eds.), Arzobispos de Toledo, mecenas universitarios, Cuenca, pp. 213-239, p. 213.

99 Paloma CuenCA MUÑOZ, El legado testamentario... [ver n. 2], p. 315. 
de cruz con cabujones en los extremos, fechado en el primer tercio del siglo XV y reutilizado como tapa de un cáliz (ca. 1500), en cuyo reverso habría ido incrustada la mencionada reliquia, acompañada de una inscripción en la que se puede leer de manera parcial: «CR / UCIS / PEI / IIMICI» ${ }^{100}$ (fig. 13).

La devoción pasional fue, además, propia de los ámbitos reformistas de la Orden de Predicadores, corriente espiritual con la que, como se ha indicado, Barrientos estaría plenamente familiarizado. En ámbitos italianos es frecuente encontrar superiores observantes, como fray Juan de Torquemada o san Antonino de Florencia, representados a los pies de la Cruz en una actitud orante, similar a la de la efigie funeraria

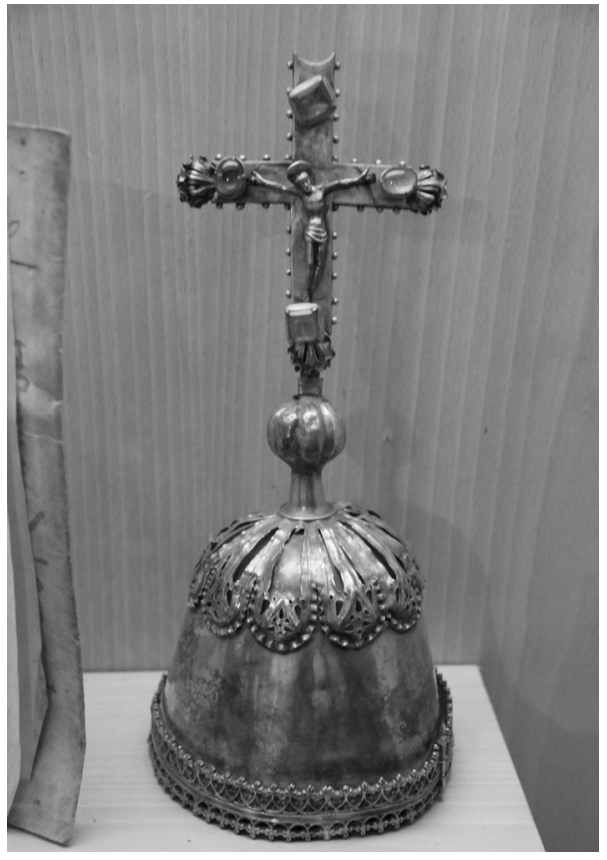

Figura 13. Cruz-relicario. Museo de las Ferias, Medina del Campo. de Barrientos. La relación entre el culto a la Cruz y el espíritu reformador está igualmente presente en otros ámbitos del siglo XV castellano como, por ejemplo, el convento de Escalaceli -el primer cenobio dominicano castellano observante, fundado en 1423 en plena sierra cordobesa por el beato Álvaro de Córdoba, confesor de la reina Catalina de Lancaster y vicario general de los primeros conventos observantes de la Provincia de España- habría albergado el primer viacrucis de Europa. A ello habría que añadir la presencia de los arma Christi y las Cinco Llagas en los vanos del claustro del Moral de Santo Domingo el Real de Toledo. En definitiva, todos estos motivos remitirían, a fin de cuentas, a las prácticas penitenciales promovidas en contextos reformistas, cuyo fin último habría de ser la imitatio Cbristi $^{101}$.

100 Manuel ARIAS, Sobrecopa con cruz relicario, en Mercaderes y Cambistas, Medina del Campo, 1998, p. 62.

101 Diana LuCÍA GómEZ-CHACón, Arte y reforma dominicana en el siglo XV: nuevas perspectivas de estudio, en Erasmo: Revista de Historia bajomedieval y moderna, 4 (2017), pp. 87-106, pp. 93 y 104106. 


\section{CONCLUSIÓN}

Movido por su celo reformador y respaldado por la protección real, Barrientos habría impulsado diversas fundaciones hospitalarias a lo largo de toda su vida, como parte de un ambicioso proyecto memorial con fines redentores. Esta iniciativa fundacional de centros asistenciales habría culminado en 1447 con la creación y dotación de su hospital de la Piedad -que en 1454 se convirtió en su heredero universal-, en Medina del Campo, villa de la que era natural y en cuyo convento de San Andrés profesó. Según consta en la súplica enviada en 1447 a Nicolás V, con esta fundación, el prelado, una vez alcanzada su «sexta edad»y, por lo tanto, ajeno ya al «deleite de las cosas visibles», habría deseado «transformar las cosas terrenales en celestiales, y las cosas transitorias en eternas».

Este deseo le habría llevado a fundar en este preciso hospital su propia capilla funeraria -independiente de la de sus progenitores, sepultados en la capilla de las Once Mil Vírgenes de la iglesia del convento de San Andrés-, a modo de «presbiterio privatizado», cubierto en origen por una armadura de madera con decoración de lazo. Con este proyecto, Barrientos no solo habría querido dejar memoria de su persona, sino también de su linaje, del cual fue fundador gracias a un privilegio que el todavía príncipe Enrique le concedió y que una desaparecida «inscripción de friso» recordaba. De este conjunto funerario, demolido en 1932, tan solo conservamos la extraordinaria efigie del obispo, obra atribuida a Egas Cueman, y un perro en alabastro, que parece acompañarla, pudiendo haber sido realizados ambos en 1454 .

La contratación por parte de Barrientos de uno de los principales escultores activos por aquellos años en Castilla sería una muestra más del especial interés del obispo por su último proyecto artístico. El elevado nivel técnico de Egas Cueman habría de garantizar la magnificencia de la obra y, con ello, la fama del comitente. $\mathrm{El}$ interés de Barrientos por la vanguardia artística del momento habría quedado plasmado, asimismo, en el modelo funerario encargado, el cual remite de manera clara a la escultura de Pedro I de Castilla, fechada en torno a 1446. En el caso que nos ocupa, dicha decisión no parece haber sido resultado de un conocimiento directo por parte de Barrientos de la tradición escultórica transpirenaica, sino de un deseo de seguir la tradición escultórica funeraria iniciada por la imagen del malogrado monarca, que el prelado habría tenido oportunidad de ver en persona. De hecho, a través de las palabras que Barrientos recoge en su testamento, sabemos que este adoptó un rol especialmente activo en el diseño y configuración de su capilla funeraria, tal como deja claro al mencionar que su cuerpo habría de ser depositado «debaxo del vulto de alabastro segund e por la vía que lo nós 
tenemos fecho e ordenado, en medio de la dicha nuestra capilla del dicho nuestro hospital» ${ }^{102}$.

Por otro lado, la dedicación del hospital de Medina del Campo a la Piedad, así como la decoración de su efigie funeraria con ángeles que portan los arma Christi, sumado a la cruz potenzada del nudo del cáliz de Barrientos, y el lignum crucis engastado, en origen, en el relicario en forma de cruz que el prelado donó a su hospital, subrayan la devoción pasional del obispo -habitual entre los prelados dominicanos reformistas-. Quizás por todo ello, la imagen que Barrientos deseó legar de si mismo a la posteridad no es otra que la de un miles Christi cubierto por las armas de Cristo, «como alguien que va a morir y no ha de volver a tener trato con esta vida» ${ }^{103}$.

\section{REFERENCIAS BIBLIOGRÁFICAS}

Aguadé Nieto, Santiago, Crisis de subsistencia, rentas eclesiásticas y caridad en la Castilla de la segunda mitad del siglo XV, en Estudios en memoria del Profesor D. Salvador de Moxó, tomo I, Madrid, 1982, pp. 21-48.

Alonso-Getino, Luis G., Dominicos españoles confesores de reyes, en Ciencia Tomista, XIV, 41 42 (1916), pp. 374-451.

- Centenario y Cartulario de nuestra Comunidad, en Ciencia Tomista, 59 (1919), pp. 129-152.

- Vida y obra de Fr. Lope de Barrientos, Salamanca, 1927.

ÁlvareZ VILlar, Julián, La Universidad de Salamanca. Arte y tradiciones, Salamanca, 1993.

A.M.T.: Testamento del Cardenal Cervantes, en Boletín de la Real Academia Sevillana de Buenas Letras, 41 (1924), pp. 121-131.

ANDRÉs ORDAX, Salvador, Autoridad plástica y eco fundacional del Colegio de Santa Cruz de Valladolid, en Fernando LlamaZares RodríGuEZ y Juan Carlos VizueTE MENDOZa (eds.), Arzobispos de Toledo, mecenas universitarios, Cuenca, pp. 213-239.

ARAujo, Fernando, La Reina del Tormes. Guía bistórico-descriptiva de la ciudad de Salamanca, Salamanca, 1884.

ARIAS, Manuel-HeRnáNDEZ, José Ignacio, Piezas para el recuerdo de un gran prelado, en Antonio SÁNCHEZ DEL BARRIO (coord.), La escultura de Lope de Barrientos en el Museo del Prado, Medina del Campo, 2015.

Beltrán de Heredia, Vicente, Bulario de la Universidad de Salamanca, Salamanca, 1966, tomo I.

Beltrán DE Heredia, Vicente, Cartulario de la Universidad de Salamanca. La Universidad en el Siglo de Oro, Salamanca, 1970, tomo II.

102 Paloma Cuenca Muñoz, El legado testamentario... [ver n. 2], p. 309.

103 Enrique Suso, Diálogo... [ver n. 79], p. 73. 
BOUREAU, Alain, «Vitae fratrum, vitae patrum». L'ordre dominicain et le modèle des péres du désert au XIIIe siècle, en Mélanges de l'École française de Rome. Moyen-Age, Temps modernes, vol. 99, n. ${ }^{\circ} 1$ (1987), pp. 79-100.

CAmpbell, Lorne y PÉREZ Preciado, Juan José, Egas Cueman, Fray Lope de Barrientos, en Lorne CAMPBELL (ed.), Rogier van der Weyden y los reinos de la península Ibérica, Madrid, 2015.

Cañas GálveZ, Francisco de Paula, El itinerario de la Corte de Fuan II de Castilla (1418-1454), Madrid, 2007.

CAÑAS REÍllo, José Manuel, Epitafio del obispo Lope de Barrientos, ca. 1469, en Corpus epigráfico conquense, 2010.

Carriazo Arroquía, Juan de Mata (ed.), Refundición de la Crónica del Halconero, Madrid, 1946.

CaStán LanaSPa, Javier, A propósito del testamento del Cardenal Tavera, en Boletín del Seminario de Estudios de Arte y Arqueología, 59 (1993), pp. 365-378.

Chao Castro, David, La estatua sepulcral de Pedro I: ¿la importación de un modelo transpirenaico?, en Concepción CoSmen, María Victoria HERráEZ y María PELlón GómEZCALCERRADA, El intercambio artístico entre los reinos hispanos y las cortes europeas en la Baja Edad Media, León, 2009, pp. 103-125.

- Egas Cueman en Castilla y el desarrollo de la tipología sepulcral con imagen orante, en Rogier van der Weyden y España. Actas del Congreso Internacional, Madrid, 2015, pp. 43-56.

CENDÓN FERNÁNDEZ, Marta, La indumentaria episcopal como reflejo de poder en la escultura funeraria bajomedieval, en Estudios in Memoriam del Prof. Dr. Fernando Galván Freile, León, 2011, pp. 101-120.

- El obispo ante la muerte en la Castilla de los Trastámara, en Archivo ibero-americano, LXVII, 258 (2007), pp. 677-708.

CORDOLIANI, Alfred, Les manuscrits du comput ecclésiastique des bibliothèques de Madrid (2ème série), en Hispania Sacra, VIII, 15 (1955), pp. 177-208.

Creytens, Raymond, L'obligation des constitutions dominicaines d'après le Bx. Jean Dominici, O.P., Archivum Fratrum Praedicatorum, XXIII (1953), pp. 207-235.

Cuenca Muñoz, Paloma, Lope de Barrientos. Tratado de la divinança, tesis doctoral, Universidad Complutense de Madrid, 1992.

- El legado testamentario de Lope de Barrientos, en Espacio, Tiempo y Forma. Serie III. H. ${ }^{a}$ Medieval, 9 (1996), pp. 303-326.

DAVIS, Adam J., Hospitals, Charity, and the Culture of Compassion in the Twelfth and Thirteenth Centuries, en Approaches to Poverty in Medieval Europe. Complexities, Contradictions, Transformations, c. 1100-1500, Turnhout, 2016.

DÍAZ IBÁÑEZ, Jorge, Pobreza y marginación en la Castilla bajomedieval. Notas sobre el ejercicio de la caridad en Cuenca a fines de la Edad Media, en Anuario de Estudios Medievales, 24 (1994), pp. 887-924.

- La Iglesia de Cuenca en la Edad Media (siglos XII-XV). Estructura institucional y relaciones de poder, tesis doctoral, Universidad Complutense de Madrid, 1996.

DíEZ Hermano, María José, Escribir para administrar: los censos del Hospital de la Piedad de Medina del Campo en época moderna, en Funciones y prácticas de la escritura. I Congreso de Investigadores Nóveles en Ciencias Documentales, Madrid, 2013, pp. 49-56. 


\section{DIANA LUCÍA GÓMEZ-CHACÓN}

ESPAÑOL BERTRÁN, Francesca, Encuadres arquitectónicos para la muerte: de lo ornamental a lo representativo. Una aproximación a los proyectos funerarios del tardogótico bispano, en Codex Aquilarensis, 31 (2015), pp. 93-120.

Fontaneda Pérez, Eugenio, El Hospital de la Piedad y San Antonio Abad o del obispo de Barrientos, en Eufemio LORENZO, Historia de Medina del Campo y su tierra, vol. I: Nacimiento y expansión, Valladolid, 1986.

Gallent Marco, Mercedes, Historia e historia de los hospitales, en Revista d'bistoria medieval, 7 (1996), pp. 179-191.

GARCÍA-Monge CARRETERO, María Isabel, Estudio y edición crítica del «Tratado del dormir y despertar» de Lope de Barrientos, tesis doctoral, Universidad Complutense de Madrid, 2001.

Inventario general de manuscritos de la Biblioteca Nacional, tomo XI (5700 a 7000), Madrid.

LóPEZ ALONSO, Carmen, La pobreza en la España medieval. Estudio Histórico-Social, Madrid, 1986. LóPeZ DíAZ, María Blanca, Las Artes en el siglo XV: el mecenazgo de los Arias Dávila, en Ángel Galindo García (ed.), Arias Dávila: Obispo y Mecenas. Segovia en el siglo XV, Salamanca, 1998, pp. 278-284.

López y Baena, Mateo, Memorias históricas de Cuenca y su obispado, CSIC, Ayuntamiento de Cuenca, Cuenca, 1949, vol. I.

Lozano, Juan Manuel, El testamento del Cardenal fuan de Cervantes, en Lora del Río. Feria y Fiestas Populares, 1987.

LuCÍA GÓMEZ-CHACÓN, Diana, Apariciones marianas y renovación monástica en la Castilla bajomedieval: Guadalupe y Santa María la Real de Nieva, en José Ángel GARCÍA DE CORTÁZAR y Ramón TEJA (eds.), Los monasterios medievales en sus emplazamientos: lugares de memoria de lo sagrado, Aguilar de Campoo, 2016, pp. 215-245.

- El Monasterio de Santa María la Real de Nieva. Reinas y Predicadores en tiempos de reforma (1392-1445), Segovia, 2016.

- Arte y reforma dominicana en el siglo XV: nuevas perspectivas de estudio, en Erasmo: Revista de Historia bajomedieval y moderna, 4 (2017), pp. 87-106.

MARTÍNEZ CASADO, Ángel, Lope de Barrientos. Un intelectual en la corte de fuan II, Salamanca, 1994.

MARTÍ Y MONSÓ, José, Estudios bistórico-artísticos relativos principalmente a Valladolid basados en la investigación de diversos archivos, Valladolid-Madrid, 1898-1901.

Matute y GaVIRIA, Justino, Adiciones y correcciones a Los Hijos de Sevilla ilustres en santidad, letras, armas, artes y dignidad de D. Fermín Arana de Varflora, Sevilla, 1886.

MOLINA DE LA TORRE, Francisco Javier, Epigrafía medieval y moderna en la provincia de Valladolid (987-1556), tesis doctoral, Universidad de Valladolid, 2013.

Mollat, Michel, Pobres, humildes y miserables en la Edad Media. Estudio social, México D.F., 1988.

Moraleja Pinilla, Gerardo, Historia de Medina del Campo, Medina del Campo, 1971.

Moreno Moreno, Juan Carlos, Los linajes de Medina del Campo. Concesión de un nuevo linaje a fray Lope de Barrientos, 1454, en Lope de Barrientos. Seminario de cultura, 2 (2009), pp. 141154.

MORTA, Ángel, Obras de Santa Catalina de Siena. El Diálogo, Madrid, 1955.

Newhauser, Richard G.-Russell, Arthur J., Mapping Virtual Pilgrimage in an Early Fifteenth-Century Arma Christi Roll, en Lisa H. COOPER y Andrea DENNY-Brown (eds.), The 
Arma Christi in Medieval and Early Modern Material Culture, Franham-Burlington, 2014, pp. 83-112.

NiETO GONZÁLEZ, José Ramón, Escuelas Mayores, Menores y Hospital del Estudio, siglos XIII-XX, en Luis E. RodrígueZ-SAN PEdro BeZAREs (coord.), Historia de la Universidad de Salamanca, vol. II: Estructuras y flujos, Salamanca, 2004, pp., 375-456.

NIETO SORIA, José Manuel, Los proyectos de reforma eclesiástica de un colaborador de Fuan II de Castilla: el obispo Barrientos, en Tomás Quesada Quesada. Homenaje, Granada, 1998, pp. 493-516.

NOGALES RINCÓN, David, La representación religiosa de la monarquía castellano-leonesa: la capilla real (1252-1504), tesis doctoral, Universidad Complutense de Madrid, 2009.

ORTEGa CERVIGón, José Ignacio, La acción política y la proyección señorial de la nobleza territorial en el obispado de Cuenca durante la Baja Edad Media, tesis doctoral, Universidad Complutense de Madrid, 2006.

Palazzo, Éric, Peindre c'est prier. Anthropologie de la prière chrétienne, París, 2016.

PAlOmo FernándeZ, Gema, La catedral de Cuenca en el contexto de las Grandes Canterías Catedralicias Castellanas en la Baja Edad Media, tomo II, Cuenca, 2002.

PaOleTti, John T.-RADKE, Gary M., Arte en la Italia del Renacimiento, Madrid, 2002.

PEREDA, Felipe, Las imágenes de la Discordia. Política y poética de la imagen Sagrada en la España del 400, Madrid, 2007.

PÉREZ MONZÓN, Olga, La dimensión artística de las relaciones de conflicto, en José Manuel NIETO SORIA (ed.), La monarquía como conflicto en la Corona castellano-leonesa (c. 1230-1504), Madrid.

PIÑEYRÚA, Alejandra, Caridad cristiana, asistencia social y poder politico: las instituciones hospitalarias en España (siglos XIII al XVI), en María Estela GONZÁLEZ DE FAUVE (ed.), Ciencia, poder e ideología. El saber y el hacer en la evolución de la medicina española (siglos XIV-XVIII), Buenos Aires, 2001.

Quadrado, José María, Recuerdos y Bellezas de España. Salamanca, Avila y Segovia, Barcelona, 1865.

- Sus monumentos y artes. Su naturaleza e historia. Valladolid, Palencia y Zamora, 1885.

RÁBADE OBRADÓ, María del Pilar, Religiosidad y práctica cristiana en la familia Arias de Ávila, en Ángel Galindo García (ed.), Arias Dávila: Obispo y Mecenas. Segovia en el siglo XV, Salamanca, 1998, pp. 206-208.

- Mecenazgo religioso y estrategias familiares en la Segovia del siglo XV: Diego Arias de Ávila y el Hospital de San Antonio, en Anuario de Estudios Medievales, 32/2 (2002), pp. 915-947.

REGINA, Vicenzo, Le Chiese di Napoli. Viaggio indimenticabile attraverso la storia artística, architettonica, letteraria, civile e spirituale della Napoli Sacra, Roma, 1995.

RÍSQUEZ MADRID, Antonia, Lope de Barrientos: promotor del linaje Barrientos de Cuenca, en Lope de Barrientos: seminario de cultura, 4 (2011), pp. 243-260.

RoBInson, Cynthia, Imagining the Passion in a Multiconfessional Castile. The Virgin, Christ, Devotions, and Images in the Fourteenth and Fifteenth Centuries, Pennsylvania, 2013.

Rodríguez CruZ, Águeda M., Historia de la Universidad de Salamanca, Salamanca, 1990.

Romero FernándeZ-PaCHeco, Juan Ramón, Santo Domingo el Real de Madrid. Ordenación económica de un señorí conventual durante la baja edad media (1219-1530), Salamanca, 2007.

RubIO VELA, Agustín, Pobreza, enfermedad y asistencia hospitalaria en la Valencia del siglo XIV, Valencia, 1984. 
RUIZ SOUZA, Juan Carlos, La planta centralizada en la Castilla bajomedieval: entre la tradición martirial y la qubba islámica. Un nuevo capítulo de particularismo bispano, en Anuario del Departamento de Historia y Teoría del Arte, 8 (2001), pp. 9-36.

- Castilla y la liberalidad de las artes en el siglo XV. La aceptación de la berencia de Al-Andalus: de la realidad material a los fundamentos teóricos, en Anales de Historia del Arte, 22 (2012), pp. 123161.

San Agustín, Obras completas de san Agustín. XL. Escritos varios (2. ${ }^{\circ}$, Teodoro C. Madrid (ed.), Madrid, 1995.

SAN VICENTE FERRER, Sermons de Quaresma, vol. I, Valencia, 1973.

SÁNCHEZ DEL BARRIO, Antonio, Historia y evolución urbanística de una villa ferial y mercantil. Medina del Campo entre los siglos XV y XVI, tomo I, tesis doctoral, Valladolid, 2005.

- (ed.), Simón Ruiz, mercader, banquero y fundador, catálogo de la exposición, Medina del Campo, 2016.

SÁNCHEZ GORDILlO, Alonso, Memorial sumario de los arzobispos de Sevilla y otras obras, José SÁNCHEZ HERrero (ed.), Sevilla, 2003.

SANTANDER RodrígueZ, Teresa, El Hospital del Estudio, en Luis E. RodríGUEZ-SAN PEDRO BEZARES y Juan Luis POLO RODRÍGUEZ (eds.), Historia de la Universidad de Salamanca, III.1. Saberes y confluencias, Salamanca, 2006, pp. 361-388.

SuÁREZ FERNáNDEZ, Luis, Castilla, el Cisma y la crisis conciliar (1378-1440), Madrid, 1960.

VILlarRoel GONZÁLEZ, Óscar, Las elecciones episcopales en la primera mitad del siglo XV. Realidad y representación de la «Libertas» eclesiástica, en Juan Francisco JIMÉNEZ, Jorge ORTUÑO y Jorge A. EIROA (eds.), Actas I Simposio de fóvenes Medievalistas, Murcia, 2003, pp. 261-273.

- El rey y el papa. Política y diplomacia en los albores del Renacimiento (el siglo XV en Castilla), Madrid, 2009.

- El rey y la Iglesia castellana. Relaciones de poder con fuan II (1406-1454), Madrid, 2011.

Villaseñor Sebastián, Fernando, The Artistic Promotion of Lope de Barrientos, Bishop of Segovia, Ávila and Cuenca, en M. ${ }^{a}$ Victoria HerráeZ, M. ${ }^{a}$ Concepción Cosmen, M. ${ }^{\text {a Dolores }}$ TEIJEIRA y José Alberto MORÁIs MORÁN (eds.), Obispos y catedrales. Arte en la Castilla bajomedieval, Berna, 2018, pp. 183-220. 